\title{
Globalización, reforma judicial y Estado de derecho en Colombia y América Latina: el regreso de los programas de derecho y desarrollo
}

\author{
César A. Rodríguez Garavito*
}

Fecha de recibido: febrero 23 de 2006

Fecha de aprobación: marzo 24 de 2006

\section{RESUMEN}

Desde la década de 1990 América Latina presenció importantes transformaciones del sistema judicial, acompañados del fortalecimiento del Estado de derecho, temas que desde hace más de un lustro son materia de análisis por parte de investigadores sociales, sin embargo, muchas de estas investigaciones desconocen los antecedentes históricos y políticos de estas reformas. Desde un análisis geográfico que permite establecer un marco comparativo regional y retomando los antecedentes históricos que desde la década de 1960 se presentaron alrededor del los sistemas jurídicos, el texto presenta los principales cambios de la reforma judicial en Colombia y América Latina.

\section{PALABRAS CLAVE}

Reforma judicial, derecho y desarrollo, enseñanza del derecho, globalización.

Profesor y Director del Centro de Investigaciones Sociojurídicas (CIJUS) de la Universidad de Los Andes, y miembro fundador del Centro de Estudios de Derecho, Justicia y Sociedad (Dejusticia). 


\section{ABSTRACT}

Since the nineties decade Latin America saw important transformations of the judicial system, accompanied of a strengthening of the state of right. Since more than a lustrum this subject has been object of analysis by social investigators, nevertheless many of this investigations have forgotten the historic and politic background of these reforms. From a geographic analysis that allows to establish a comparative regional frame, and retaking the historic background that since the sixties were presented around the juridical systems, the article presents the main changes in the judicial reform in Colombia and Latin America.

\section{Key words}

Judicial reform, law and development, teaching of law, globalization.

A lo largo y ancho de América Latina, la reforma del sistema judicial y el fortalecimiento del Estado de derecho están en el centro de los debates políticos y académicos. En Brasil, el enfrentamiento público entre los jueces y el gobierno sobre la reforma y la independencia judiciales se convirtió en uno de los temas más difíciles en los primeros años de la administración de Luiz Inácio Lula da Silva. En tanto que Lula nombraba, en 2003, un funcionario dedicado exclusivamente a la reforma de las cortes para abrir y transformar lo que el mandatario brasileño llamaba la caja negra de la justicia, el presidente de la Corte Suprema respondía que "Lula simplemente no entiende el funcionamiento de la administración de justicia" (O Globo, 2003: 1-3; The Economist, 2004: 37). En Argentina, tras la escandalosa manipulación de la Corte Suprema y del sistema judicial por parte del gobierno de Carlos Menem (véase Verbitsky, 1993), una de las prioridades de la administración de Néstor Kirchner ha sido la depuración de la Corte y el sistema judicial. En Colombia, como se documenta a lo largo de este documento, la reforma judicial ha sido también tema protagónico de las discusiones públicas durante los últimos quince años, desde aquellas que versan sobre los ajustes a la justicia civil y penal hasta aquellas que tratan sobre la justicia constitucional. La situación es similar en los demás países de la región, donde iniciativas tan diversas como el aumento del salario de los jueces, la expedición de nuevos códigos civiles y de procedimiento y la agilización de los juicios comerciales y penales tienen un lugar muy destacado en las agendas de políticas públicas.

Junto con las políticas y debates sobre la reforma judicial y el Estado de derecho (rule of law) ${ }^{1}$, en los últimos años se han multiplicado los estudios sobre el tema, como lo muestra el balance bibliográfico está presentado. Sin embargo, los estudios existentes en América Latina en general, y en Colombia en particular, tienen dos limitaciones importantes, una de carácter geográfico y otra de tipo histórico. Por un lado, dada la tendencia de los estudios sociales y jurídicos a concentrarse en la escala nacional, escasean los análisis comparativos y regionales que teoricen y documen-

Utilizo la expresión Estado de derecho como equivalente aproximado del término inglés rule of law -que es la expresión corriente en la bibliografía internacional sobre el tema - para referirme al sistema político y legal en el que gobernantes y gobernados están sujetos al imperio de la ley. En términos más precisos, "el Estado de derecho (rule of law) puede ser definido como un sistema en el que las leyes son de conocimiento público, tienen un significado claro, y se aplican a todos por igual", lo que implica que "las instituciones centrales del sistema jurídico -incluyendo las cortes, la Policía y la Fiscalía - son justas, competentes y eficientes" y que el gobierno "es regulado por un marco jurídico comprehensivo, de tal forma que sus funcionarios aceptan que el derecho se aplica a su propia conducta" (Carothers, 2006a: 4). 
ten las evidentes conexiones que hay entre los programas sobre la reforma judicial y el Estado de derecho en los distintos países. En otras palabras, a pesar de que, como se verá en este capítulo, muchos de los actores y temas de estas reformas son los mismos en los múltiples programas nacionales, la mayor parte de la bibliografía los sigue tratando como si fueran experimentos aislados. De esta forma, se dejan de lado los vínculos regionales y globales que ayudan a explicar el surgimiento, el desarrollo y los resultados de los programas de reforma judicial y fortalecimiento del Estado de derecho.

Por otro lado, las últimas reformas son estudiadas generalmente sin hacer referencia a proyectos afines que fueron impulsados en décadas pasadas, y cuyas lecciones son muy útiles para los practicantes y analistas de la nueva ola de reformas. Esta falta de visión histórica, como se verá más adelante, explica la resurrección de políticas públicas y marcos analíticos que fueron ampliamente criticados, incluso por sus artífices, entre los años sesenta y ochenta del siglo pasado.

Este trabajo intenta contribuir a superar estos puntos ciegos de la bibliografía y el debate público mediante un análisis de la reforma judicial en Colombia y América Latina que hace hincapié en las conexiones regionales y globales entre los programas nacionales, a la vez que los inserta dentro de un proceso más prolongado que se remonta a los años sesenta. Basándome en esta perspectiva, intento dar sustento empírico y teórico a tres tesis:

En primer lugar, afirmo que los proyectos contemporáneos de reforma judicial en Colombia y Latinoamérica hacen parte de una 'segunda generación' de programas de transformación de las instituciones legales, que tiene una afinidad directa (aunque también diferencias importantes) en relación con una primera generación de pro- gramas de derecho y desarrollo (law and development), que tuvo su auge hace cuatro décadas.

En segundo lugar, muestro las tensiones internas de los programas de reforma judicial y de fortalecimiento del Estado de derecho. Sostengo que ellas revelan, a su vez, las tensiones existentes dentro del ideal liberal del Estado de derecho entre la protección igualitaria de las garantías democráticas, por un lado, y la protección de la propiedad privada y la libertad de mercado, por el otro.

En tercer lugar, al hacer un balance de los programas de reforma judicial en la práctica, mantengo que éstos han tendido a privilegiar la cara del Estado de derecho que promueve el mercado -por ejemplo, a través del relieve puesto en la reforma a la justicia civil y penal para aumentar la seguridad de los contratos y reforzar el orden público-, antes que los componentes del Estado de derecho que buscan garantizar el acceso igualitario a la justicia y la sujeción de todos los ciudadanos y gobernantes a la ley.

Estas tesis implican una posición intermedia en relación con el debate sobre la reforma judicial. Por un lado, significan una crítica a los balances, optimistas en exceso, hechos por los gobiernos de la región y por las agencias que financian buena parte de los programas - por ejemplo, el Banco Interamericano de Desarrollo (BID), el Banco mundial y la Agencia Estadounidense para el Desarrollo Internacional (AID)-. Contra esta visión, existen pruebas de que los programas han tenido un efecto mucho menor de lo esperado (Carothers, 2006a) y que han promovido una democracia y un Estado de derecho "de baja intensidad" (Santos, 2001). Al concentrarse en la protección de la propiedad privada y la garantía del orden público, dichos proyectos han marginado los elementos igualitarios que son también parte del ideario del Estado de derecho y que corres- 
ponden a una versión de "alta intensidad" de la democracia y los derechos ciudadanos.

Por el otro lado, las tesis mencionadas reconocen la urgencia de mejorar el funcionamiento del sistema judicial y de promover el acceso equitativo de toda la población a éste, así como la necesidad de fortalecer la independencia judicial y las demás garantías del Estado de derecho. Por lo tanto, contra los críticos incondicionales de estos programas, el capítulo sostiene que la consolidación de un sistema judicial eficiente, independiente y equitativo es parte central de la construcción del Estado social de derecho. Como lo han mostrado O'Donnell, Méndez y Pinheiro (1999), un sistema en el que la justicia es accesible y confiable $y$ en el que las cortes garantizan la obediencia a la ley por parte de ricos y pobres por igual puede ser un mecanismo poderoso de disminución de las desigualdades sociales y de solución pacífica de los conflictos.

Para dar sustento a estas tesis, divido el artículo en cuatro partes. En la primera delineo los fundamentos teóricos e ideológicos de la primera generación de derecho y desarrollo y describo brevemente la forma como fueron llevados a cabo los programas de este tipo en América Latina. En la segunda parte analizo las nuevas políticas sobre reformas jurídicas que han tenido lugar desde los años ochenta, especialmente las impulsadas por organismos de cooperación internacional y agencias financieras multilaterales, con el fin de transformar los sistemas judiciales de los países de la región. En la tercera sección me detengo en el caso de Colombia, uno de los países de la región que ha recibido la mayor cantidad de fondos de parte de las agencias multilaterales que han auspiciado la segunda generación de derecho y desarrollo, particularmente la AID. Como se verá, el balance de dos décadas de programas de la AID en Colombia (1986-2006) ofrece datos empíricos sobre los alcances y limitaciones de la nueva ola de programas de reforma judi- cial. Finalmente, en la cuarta sección presento las conclusiones.

\section{La primera generación de programas de derecho y desarrollo: la 'modernización' de la enseñanza del derecho en América Latina}

\section{Los orígenes y las bases teóricas e ideológicas}

Los programas de derecho y desarrollo hunden sus raíces en las políticas de asistencia de Estados Unidos, en los años sesenta, al entonces llamado Tercer Mundo. Debido a la creciente confianza de Estados Unidos en su sistema económico y político y al temor frente a la posible expansión del comunismo, el gobierno estadounidense vio en la asistencia para el desarrollo a los países pobres un mecanismo ideal para enfrentar la expansión de la brecha entre el primer mundo y el tercero y para evitar la difusión del modelo de la revolución cubana a otros países, especialmente en América Latina. Por lo tanto, durante dicho período las agencias gubernamentales y algunas organizaciones privadas estadounidenses patrocinaron el surgimiento y la consolidación de un campo de estudios sobre las condiciones necesarias para el desarrollo del Tercer Mundo (Kennedy, 2006; Trubek y Galanter, 1974; y Gardner, 1980).

Los economistas y los tecnólogos fueron los primeros en responder al llamado de dichas agencias y organizaciones, seguidos por los abogados y los estudiosos del derecho. En el campo jurídico, el resultado fue la formulación de tesis y programas que establecieron un vínculo directo entre el derecho moderno -representado, de acuerdo con esta visión, por el sistema jurídico liberal de Estados Unidos- y el desarrollo económico. Como lo han sostenido Cao (1992) y Chibundu (1997), la base teórica de los estudios de derecho y desarrollo estaba lejos de ser original. De hecho, sus pilares se encuentran en la teoría weberiana sobre el papel del derecho ra- 
cional en la consolidación de la sociedad capitalista moderna y, en este sentido, hacen parte de la teoría general de la modernización.

El modelo de liberalismo jurídico que dominó desde un comienzo los estudios de derecho y desarrollo estaba basado en el siguiente conjunto de supuestos (Trubek, 2006; y Trubek y Galanter, 1974): primero, la sociedad está compuesta por individuos que aceptan el poder estatal porque consideran que éste protege sus intereses. Segundo, el derecho es a la vez un medio de control del individuo por parte del Estado y un mecanismo de control del Estado por parte de los individuos. Tercero, las normas jurídicas son diseñadas con el fin de alcanzar objetivos comunes y son elaboradas mediante un proceso pluralista en el que están representados los intereses individuales de los miembros de la comunidad. Cuarto, las normas jurídicas son aplicadas por igual a todos los individuos. Quinto, los jueces son los principales actores del sistema jurídico y aplican imparcialmente las normas. Finalmente, se supone que, en general, las personas obedecen las normas jurídicas vigentes.

¿Cómo promueve este modelo de derecho el desarrollo económico? Los pioneros de la teoría de derecho y desarrollo entendían el desarrollo como unas características sociales, económicas y políticas relacionadas entre sí -aunque vagamente definidas y no enteramente consistentes-, como el bienestar material, la libertad y la participación política (Trubek y Galanter, 1974: 1073). LoS académicos y políticos que hicieron parte de esta corriente percibían el derecho como una herramienta indispensable para lograr estos objetivos. El derecho, en el modelo descrito, implica un gobierno despersonalizado que opera a través de reglas abstractas. De aquí se deriva una mayor igualdad ante la ley. El derecho es un instrumento para controlar la arbitrariedad y el autoritarismo y, por lo tanto, promueve la libertad individual y la responsabilidad gubernamental. Final- mente, el derecho puede ser utilizado de forma instrumental para diseñar reformas progresistas que aumenten el bienestar material general (Kennedy, 2006; y Trubek, 2006).

Es importante subrayar la noción relativamente amplia de desarrollo y el papel del derecho en el desarrollo que caracterizó a esta primera generación. Esta visión, como veremos más adelante, contrasta claramente con la concepción estrecha del desarrollo que vino a prevalecer en los comienzos de la segunda generación de derecho y desarrollo tres décadas más tarde.

\section{Los programas de reforma a la enseñanza del derecho}

Debido a la firme creencia en el potencial transformador de la educación y la familiaridad de los abogados vinculados a los programas de derecho y desarrollo con el ambiente académico, los programas de la primera ola estuvieron encaminados a reformar sustancialmente la enseñanza del derecho en el llamado Tercer Mundo. Primero en Asia, luego en África y finalmente en América Latina, la reforma a las facultades de derecho fue impulsada principalmente por la AID y la Fundación Ford. Sin embargo, los proyectos fueron respaldados directa o indirectamente por un amplio número de instituciones estadounidenses, como la American Bar Foundation o el International Legal Center, y de universidades, como Wisconsin, Stanford, Harvard, Nueva York, Columbia y Yale (Gardner, 1980: 8).

En América Latina, los programas más ambiciosos tuvieron lugar en Brasil, Chile y Colombia. En Brasil, la AID y la Fundación Ford financiaron un proyecto de reforma a la educación jurídica desde 1965, que fue canalizado a través de un centro de investigación creado por fuera de las facultades de derecho existentes, debido a la fría respuesta que estas últimas dieron a los primeros contactos hechos por la AID y la Ford (Gardner, 1980: 62). En Chile, por iniciativa del decano de 
una de las cinco facultades de derecho del país en 1966, la Fundación Ford aceptó patrocinar un programa de reforma a la enseñanza del derecho que involucró también a otras dos universidades chilenas y se convirtió en el proyecto más grande de este tipo en América Latina (Gardner, 1980: 131). Finalmente, representantes de la Fundación Ford visitaron las facultades de derecho colombianas entre 1966 y 1967 para determinar cuáles de ellas estarían dispuestas a participar en un proyecto similar a los que ya estaban en marcha en Brasil y Chile. En 1968, la Ford escogió las facultades de derecho de cinco universidades que acogieron favorablemente los planes de reforma -Los Andes, Nacional, Cauca, Externado y Antioquia-y el programa fue lanzado oficialmente (Gardner 1980)².

A pesar de las diferencias entre los tres programas y los diversos contextos sociales y políticos de los países involucrados ${ }^{3}$, dichos programas compartían una ideología y un modus operandi. En primer lugar, se limitaban a promover cambios en la educación jurídica, bien sea mediante el patrocinio de una especie de 'caballo de Troya' modernizador que penetraría en las universidades (como en Brasil), o bien mediante la colaboración directa con facultades de derecho seleccionadas para el efecto (como en Chile y Colombia). Sin embargo, los defensores de los proyectos concebían las reformas como instrumentos para alcanzar cambios sociales mucho más ambiciosos, por cuanto creían que los abogados entrenados en las técnicas y el espíritu del derecho moderno constituirían una masa crítica dentro de la burocracia estatal y el sector privado (Dezalay y Garth, 2002; y ILC, 1975).
En segundo lugar, los programas tuvieron su origen en Estados Unidos y fueron siempre controlados por instituciones de ese país. Aunque es claro que los proyectos no podrían haber sido llevados a cabo sin la participación de las universidades y los centros de investigación jurídicos locales involucrados, también es cierto que dicha participación fue limitada, dado que tanto los objetivos como los procedimientos de los proyectos seguían el modelo general definido por las instituciones estadounidenses (Trubek, 2006; y Gardner, 1980).

En tercer lugar, la estrategia que se consideró apropiada para la modernización de la enseñanza del derecho en Latinoamérica fue el transplante del modelo de educación de las facultades de derecho de Estados Unidos. En efecto, los tres proyectos evocan la definición clásica de transplante jurídico, acuñada por Alan Watson, esto es, "el traslado de una regla o sistema de reglas de un país a otro" (1974: 21). Los programas de derecho y desarrollo de la primera generación implicaban este tipo de 'mudanza jurídica transnacional', pero su objeto era un sistema de educación más que un sistema de reglas.

Es difícil clasificar estos transplantes de acuerdo con la dicotomía convencional de transplantes voluntarios y transplantes impuestos (Watson, 1974; y Snyder, 1982). Esto se debe a que aun cuando los transplantes no fueron generalmente resultado de una petición hecha por el país receptor (excepto en Chile), tampoco fueron impuestos forzosamente a ellos. Siguiendo a Gardner, se puede decir que estos transplantes fueron 'infundidos', en cuanto surgieron de "ini-

Como en los demás países involucrados, los programas de reforma colombianos se encontraron con la resistencia de sectores estudiantiles y profesorales. Según Gardner, "en todas las facultades de derecho que participaron surgió algún tipo de protesta, asamblea o amenaza de huelga estudiantil en oposición a [los planes de reforma]. Una de las facultades, la de la Universidad Nacional, se retiró del programa debido a la resistencia que éste suscitaba" (1980: 206).

3 Mientras que Brasil pasaba por una dictadura y Colombia estaba bajo un régimen democrático limitado por un pacto bipartidista, la situación política de Chile cambió drásticamente durante la vigencia del proyecto, al pasar de una democracia liberal (Frei) a una democracia socialista (Allende) y, finalmente, al régimen autocrático de Augusto Pinochet. 
ciativas premeditadas [...] alentadas por la cultura jurídica exportadora, a menudo con la participación selectiva de la cultura receptora" (1980: 33).

Los transplantes tenían cuatro componentes. Primero, las reformas implicaban la transmisión del método de enseñanza socrático, que debía reemplazar el método prevalente en América Latina, heredado de las culturas jurídicas europeas continentales y caracterizado por el predominio de la cátedra y el papel pasivo del alumno. Segundo, concebían como recurso pedagógico fundamental el análisis de casos concretos. Esto se contraponía al estudio sistemático de reglas abstractas contenidas en los códigos, que ha dominado la enseñanza del derecho en la región. Tercero, difundían la imagen instrumentalista del derecho, esto es, la imagen del derecho como herramienta para el logro de objetivos sociales escogidos deliberadamente. Esta concepción del derecho -que tiene clara afinidad con la del realismo jurídico estadounidense-contrastaba abiertamente con la heredada de los sistemas europeos, de acuerdo con la cual el derecho es un conjunto de reglas formales y unívocas que limitan la conducta de los actores privados y públicos. Por último, y en estrecha relación con el aspecto anterior, el modelo proponía una concepción del abogado como ingeniero social que sería capaz de usar su conocimiento del derecho de forma creativa para resolver una multitud de problemas sociales apremiantes. Este modelo contrastaba con la visión continental de los abogados como guardianes imparciales del orden jurídico (Gardner, 1980).

Los programas dieron prioridad a los dos primeros aspectos del modelo, esto es, a la transmisión de un método de enseñanza que combinaba la pedagogía socrática con el análisis de casos. Como lo han sostenido David Trubek y Marc Galanter (1974), dos de los participantes más conspicuos de estos programas, la primera generación de académicos y funcionarios involucrados en programas de derecho y desarrollo creía en la existencia de una conexión íntima entre todos los elementos del modelo liberal de derecho, de tal forma que la promoción de la transferencia de uno de dichos elementos a los países receptores (esto es, el método de enseñanza del derecho prevalente en Estados Unidos) desencadenaría la transformación de los demás aspectos de la educación y la práctica de los abogados en América Latina. En consecuencia, sumas considerables (cerca de cinco millones de dólares en total) fueron destinadas a, entre otras cosas, enviar profesores estadounidenses a Latinoamérica y a entrenar profesores latinoamericanos en las artes del método de caso, así como a patrocinar la participación de académicos latinoamericanos en seminarios especialmente diseñados con este fin y dictados en universidades de Estados Unidos.

\section{El fracaso de la primera generación}

¿Cuáles fueron los resultados de estos programas? En términos generales, existe un consenso acerca del fracaso de los esfuerzos de la primera generación por modernizar la educación jurídica en América Latina de acuerdo con el modelo del liberalismo jurídico estadounidense. La evaluación de los proyectos hecha tanto por las instituciones (ILC, 1974) como por los individuos que participaron en ellos (Trubek y Galanter, 1974; y Gardner, 1980) mostraba un claro desencanto hacia mediados de la década de los setenta. Los balances más recientes llegan a la misma conclusión (Kennedy, 2006; Dezalay y Garth, 2002; y Trubek, 2006). Si, de acuerdo con Watson, "un transplante jurídico exitoso crece en el nuevo cuerpo y pasa a ser parte de él de la misma forma como una regla o institución se habría seguido desarrollando en el sistema del cual fue transplantado" (1974: 27), entonces el transplante a América Latina del método socrático y el análisis de casos no tuvo éxito.

Ninguno de estos dos elementos fue adoptado por la mayoría de las facultades de derecho latinoamericanas que participaron en los programas 
y, mucho menos, por la comunidad jurídica en su conjunto. De hecho, la enseñanza en la mayoría de las facultades de derecho de la región se caracteriza, hoy como ayer, por el predominio de la cátedra y el estudio de los códigos. Entre tanto, el transplante de los otros dos componentes del modelo -esto es, la visión instrumentalista del derecho y de los abogados- no tuvo efectos notorios o, en el peor de los casos, resultó siendo contraproducente. Dicha visión fue estratégicamente adoptada por sectores de los Estados chileno y brasileño, pero para beneficio de los burócratas mismos antes que de la ciudadanía. De hecho, por lo menos en Brasil, el uso instrumental del derecho tendió a favorecer en el largo plazo al régimen autoritario (Gardner, 1980)4.

De acuerdo con la evaluación hecha por los propios actores de la primera generación, los programas fracasaron por dos razones. En primer lugar, los proyectos fueron etnocéntricos e ingenuos, en cuanto acogieron incondicionalmente el modelo estadounidense de enseñanza del derecho y buscaron transplantarlo a América Latina sin tener en cuenta la cultura jurídica y las condiciones sociales de cada lugar (Trubek, 2006; Trubek y Galanter, 1974; y Gardner, 1980). En segundo lugar, chocaron con los poderosos intereses protegidos por el sistema prevalente en América Latina, dado que dicho sistema permitía a profesores y estudiantes dedicar sólo tiempo parcial a la universidad y era económico para las facultades de derecho.

Como resultado del desencanto con estos proyectos y otros similares, la financiación para las reformas al derecho en el llamado Tercer Mundo disminuyó rápidamente, y el vínculo entre dere- cho y desarrollo se convirtió en un campo de investigación más que de acción ${ }^{5}$. El tono escéptico radical de los trabajos académicos producidos en el ocaso de los programas de derecho y desarrollo pasó a dominar la bibliografía sobre el tema y se extendió a algunas corrientes de la teoría y la sociología del derecho.

En efecto, tanto el trabajo de Gardner como el de Trubek y Galanter -los más influyentes en la fase terminal de derecho y desarrollo- son prácticamente epitafios de esta corriente. Esto explica por qué Francis Snyder abrió el comentario que escribió sobre el libro de Gardner diciendo que "el movimiento de derecho y desarrollo en Estados Unidos está hoy casi muerto" (1982: 373). Las repercusiones del desencanto de la primera generación de actores y promotores de programas de derecho y desarrollo afectaron no sólo el futuro de dichos programas, sino también la fe en el sistema jurídico liberal estadounidense en general. En este sentido, fue muy importante el hecho de que la experiencia en América Latina mostró que los abogados estaban mucho menos comprometidos con el cambio social que lo que se había creído en un principio y que el derecho podía ser un poderoso mecanismo conservador del statu quo. En resumen, los programas de la primera generación, como Trubek y Galanter lo han afirmado, mostraron la 'cara oscura' del derecho:

Las reformas al derecho diseñadas para transformar aspectos centrales de la vida social y promover el desarrollo pueden de hecho convertirse en una forma de política simbólica que, en lugar de promover el cambio, puede impedirlo al servir como argumento contra la protesta popular y fortalecer los grupos favorecidos por el statu quo.

Dado que -aparte del estudio clásico de James Gardner (1980), que se ocupa sólo del fracaso de los proyectos- no existen análisis sistemáticos sobre la repercusión de los programas en las facultades de derecho de Brasil, Chile y Colombia, es difícil encontrar casos en los que las reformas hayan tenido éxito. Esto no significa, sin embargo, que todos los programas hayan fracasado. Por ejemplo, en Colombia la Facultad de Derecho de la Universidad de los Andes, que fue fundada en el momento en el que el programa de la Fundación Ford estaba comenzando, adoptó desde un principio la enseñanza de corte socrático y el método de caso.

$5 \quad$ Entrevista con Clarence Días, director del International Center for Law in Development, Nueva York, 11 de octubre de 1998. 
Además, la combinación de una creciente racionalidad jurídica instrumental y una mayor regulación estatal de la economía puede contribuir al bienestar económico de una pequeña élite, dejando a la mayoría en la misma situación, o incluso en una peor (1974: 1084).

En esta afirmación ya se vislumbra el tono pesimista y escéptico radical que caracterizaría más tarde los estudios críticos del derecho (critical legal studies [CLS]) y a algunos de los sectores de la sociología del derecho en Estados Unidos (véase Rodríguez Garavito, 1999). De hecho, algunos de los teóricos y practicantes de los programas de derecho y desarrollo participaron activamente en la fundación de la corriente de CLS y vieron en esta transición una forma de pasar de una era 'imperialista' a una 'postimperialista' en el estudio del derecho (Trubek, 1990).

Las críticas a la primera generación no provinieron únicamente de sus artífices, ni su resultado fue sólo el pesimismo de los círculos intelectuales estadounidenses. Desde los países del Sur global que fueron receptores de los programas surgieron, igualmente, aproximaciones críticas y propuestas alternativas. Inspirados en el desafío de la teoría de la dependencia a la teoría de la modernización, juristas en América Latina y el sureste asiático impulsaron en los años setenta un movimiento que, bajo el nombre de el derecho y el otro desarrollo ( law and another development), propuso una profunda revisión de los conceptos de desarrollo económico y de derecho que dominaron los programas de primera generación (Ghai, 1978; y ICLD, 1978). Dado que este artículo se concentra en estos últimos y en la segunda ola de reformas que los sucedieron a partir de los años ochenta, no es éste el lugar para examinar con detalle esta importante corriente alternativa. Importa, sin embargo, resaltar dos aportes de este movimiento disidente, que han influido en la discusión y evolución de los programas convencionales de derecho y desarrollo:
Por un lado, el movimiento ha defendido un concepto de desarrollo alternativo que, al darle relieve a la satisfacción de las necesidades humanas de las poblaciones marginadas y a la participación ciudadana, se contrapone a la atención puesta en las metas de crecimiento económico y la gestión vertical de las políticas públicas típicas de los proyectos convencionales de desarrollo. Las versiones contemporáneas de esta visión se han convertido en influyentes críticas a los programas actuales de ajuste estructural y los recientes proyectos de reforma legal.

Por el otro, las organizaciones y autores que participaron en esta corriente pasaron a ser protagonistas del movimiento de derecho alternativo en América Latina, que desde la década de los setenta ha promovido formas de regulación, de interpretación judicial y de ejercicio del derecho que sirvan como mecanismos de transformación social (véase Rodríguez Garavito, 2006; y Souza, 2001). No es casual, por lo tanto, que algunas de las organizaciones pioneras de este importante movimiento sean hoy también protagonistas en los debates sobre las limitaciones de los nuevos programas de derecho y desarrollo (véase ILSA, 2001).

En resumen, debido a sus pobres resultados y a críticas internas y externas, los programas de primera generación declinaron rápidamente y dieron lugar a un período caracterizado por un profundo escepticismo en relación con el derecho y su papel en la producción de cambios sociales estructurales, en general, y en el logro del desarrollo económico a gran escala, en particular. De hecho, los estudios más influyentes escritos sobre el tema en los años setenta pueden ser vistos como esfuerzos de antiguos actores de los proyectos de derecho y desarrollo por saldar cuentas con el pasado y pasar a una nueva fase más académica y de pretensiones más modestas (Gardner, 1980; y Trubek y Galanter, 1974). De ahí 
que no haya otra área de políticas y estudios sociojurídicos cuya muerte haya sido más documentada $-y$, con frecuencia, deseada- que la de derecho y desarrollo.

\section{Globalización y reforma judicial: la segunda generación de derecho y desarrollo}

\section{Orígenes de la segunda generación}

El anuncio del fin de los programas de derecho y desarrollo resultó ser prematuro. Como lo reconoció últimamente uno de los autores principales del réquiem de dichos programas:

Los rumores de su muerte fueron exagerados. Hoy en día, el negocio de la reforma jurídica en los países en desarrollo es muy boyante, hasta el punto de superar incluso los sueños más ambiciosos de los pioneros de la [primera generación] de derecho y desarrollo. Agencias como el Banco Mundial, que antes se dedicaban principalmente a construir carreteras y embalses y a promover el equilibrio macroeconómico, hoy proclaman la importancia del "Estado de derecho" (rule of law) y gastan miles de millones de dólares en reformar los sistemas jurídicos de países tan diversos como Albania, Argentina, Bangladesh o Bolivia (Trubek, 2006: 34).

¿Cómo se explica la resurrección de los programas de reformas al derecho y a las instituciones jurídicas? El nacimiento de la segunda generación está enraizado en dos transformaciones históricas relacionadas entre sí. Por un lado, la caída de la Cortina de Hierro renovó el optimismo en relación con las virtudes de la democracia y el capitalismo liberales. En términos prácticos, el abandono de las instituciones de la era comunista en Rusia y los países de Europa del Este creó una demanda masiva por nuevas instituciones de corte liberal (incluidas las del Estado de derecho), que han sido transplantadas al por mayor por los actores de la segunda generación. Por el otro, en regiones de la periferia capitalista como América Latina, los años ochenta y noventa estuvie- ron marcados por el pensamiento económico y las políticas públicas asociadas con el Consenso de Washington.

Este giro neoliberal abrió la puerta a nuevos programas ambiciosos de reformas estructurales, inspirados en una confianza renovada en las virtudes de un mercado desregulado. Según se explica en dicho capítulo, después de una primera ola de reformas neoliberales en los años ochenta -centrada exclusivamente en variables económicas como la disminución del déficit fiscal y la apertura de los mercados nacionales-, en los años noventa agencias como el Banco Mundial, el BID y la AID incluyeron en su menú de reformas un fuerte componente institucional.

Este giro institucional de las políticas de ajuste estructural -del que hacen parte los programas de reforma judicial y fortalecimiento del Estado de derecho que clasifico bajo la segunda generación de derecho y desarrollo- resultó del efecto combinado de tres factores. El primero fue la evidencia de los pobres resultados de las políticas neoliberales en países con una marcada debilidad institucional. En efecto, las consecuencias desastrosas de las reducciones drásticas de los aparatos estatales, provocadas por los programas radicales de ajuste estructural -piénsese, por ejemplo, en los colapsos de Rusia, en 1998, y Argentina, en 2001-, confirmaron lo que los críticos del Consenso de Washington habían advertido desde un principio: que el Estado, antes de ser parte del problema (como lo sostuvieron los reformadores neoliberales), era parte de la solución, en la medida en que una economía de mercado depende de un Estado robusto para funcionar adecuadamente.

De ahí que incluso los artífices del Consenso abogaran por el inicio de una segunda etapa de reformas que incluía el fortalecimiento, aunque muy selectivo, del Estado -específicamente de las instituciones esenciales para la protección de la pro- 
piedad privada, la seguridad de los contratos y el orden público (Williamson, 2003; y Naím 1994 y 2000)-. La autocrítica a los programas iniciales de ajuste estructural y el giro hacia las instituciones y la reforma judicial son evidentes, por ejemplo, en los documentos recientes del Banco Mundial sobre el tema:

La experiencia práctica mostró que los esfuerzos reformadores no podían limitarse a impulsar políticas de achicamiento del Estado [...] Aunque el enfoque teórico inicial buscaba principalmente resaltar los problemas generados por las instituciones estatales, la práctica mostró que la solución no consistía simplemente en desmantelar el Estado, desregular y privatizar [...] Descubrimos, entonces, que la falta de atención a las instituciones, en especial las relacionadas con el derecho, limitaba severamente el alcance de las reformas que buscaban el desarrollo económico y la reducción de la pobreza (Banco Mundial, 2002: 17-18).

La reivindicación de la importancia de las instituciones fue hecha igualmente desde la academia. De hecho, el segundo factor decisivo del giro hacia los programas de fortalecimiento institucional fue el ascenso del neoinstitucionalismo dentro del pensamiento económico, (véanse North, Summerhill y Weingast, 2002; y North 1990).

El tercer factor determinante, específicamente en América Latina, fue el proceso de democratización de los años ochenta, que trajo consigo el fortalecimiento de la sociedad civil y de los grupos que dentro de ella abogaron por la garantía de los derechos humanos y la separación de poderes. El desmonte de los aparatos estatales de las dictaduras latinoamericanas implicó, por lo tanto, transformaciones constitucionales que incluyeron la introducción o fortalecimiento de un sistema judicial independiente y los demás elementos del Estado de derecho. A pesar de las diferencias radicales y la oposición explícita entre la agenda de los derechos humanos y la agenda neoliberal, una y otra han resaltado la importancia de la reforma judicial y el fortalecimiento del Estado de derecho (Keck y Sikkink, 1998; Dezalay y Garth, 2002). Como se verá enseguida, sin embargo, el claro contraste entre las concepciones de la democracia, del Estado de derecho y de la reforma judicial que defienden los promotores de estas dos agendas hace problemático incluirlas sin más en un mismo grupo.

Por lo tanto, hacia comienzos de la década de los noventa, el panorama geopolítico e intelectual era propicio para la resurrección del movimiento de derecho y desarrollo. De hecho, las condiciones para la difusión del Estado de derecho y el capitalismo liberal eran mucho más favorables que en los años sesenta y setenta. Basta pensar en que los potenciales países receptores se habían multiplicado, porque entre ellos figuraban ahora no sólo los que participaron en los programas de la primera generación, sino también aquellos que en el pasado estaban excluidos por ser parte del área de influencia soviética.

En síntesis, las transformaciones políticas y económicas recientes crearon las condiciones no sólo para la globalización de los mercados de bienes, servicios y capitales, sino también para el renacer de la cuestión del papel del derecho en el desarrollo. Esto no resulta sorprendente cuando se tiene en cuenta, como McMichael (2000) lo ha puesto de presente, que existe una afinidad clara entre, por una parte, las prácticas y los discursos sobre el desarrollo que surgieron en la segunda posguerra y alcanzaron su punto más alto en las décadas de los sesenta y los setenta y, por otra, aquellos que constituyen la médula de la globalización contemporánea.

No sorprende, entonces, que los protagonistas de la segunda ola de derecho y desarrollo sean las instituciones que han impulsado la globalización de los mercados mediante la promoción de ajustes estructurales en los países de la periferia 
capitalista. En efecto, el Banco Mundial (en la escala global) y el BID (en la escala regional) han promovido activamente programas de reforma al derecho en estos países (Dakolias, 1996, 2001; BID, 1993; Biebesheimer, 2001; y Rowat, Malik y Dakolias, 1995). La AID, también promotora de la apertura de los mercados nacionales alrededor del mundo, es el tercer actor principal de la segunda generación (Sarles, 2001; y Vaky, 1998).

Desde el ángulo de los derechos humanos, otras reformas al derecho y las prácticas jurídicas han sido impulsadas por organizaciones gubernamentales y no gubernamentales que buscan consolidar las garantías democráticas en América Latina. Esto explica, por ejemplo, el impulso del Programa de las Naciones Unidas para el Desarrollo (PNUD) a reformas judiciales en la región (Obando, 1998), así como el apoyo de la Fundación Ford a nuevos programas de abogacía de interés público, acceso a la justicia y promoción de las libertades civiles y los derechos sociales (Fundación Ford, 2000). Desde esta perspectiva también los gobiernos europeos han tendido a financiar proyectos de reforma al derecho en las últimas décadas (Henao, 1991).

Esta breve enumeración de las instituciones promotoras pone ya de presente la gran diversidad de actores, objetivos, metodologías y orientaciones políticas de los nuevos programas de reforma al derecho y la justicia. Esta diversidad tiende a ser soslayada por autores que incluyen bajo una problemática categoría genérica de "globalizadores jurídicos" o "promotores de la agenda del Estado de derecho" a actores tan diferentes como los bancos multilaterales y las organizaciones de derechos humanos (Dezalay $y$ Garth, 2002; y Trubek, 2006).

Como lo hemos mostrado en otro lugar (Santos y Rodríguez Garavito, 2005), existen profundas diferencias entre las bases teóricas, las audiencias y los propósitos de las formas de globalización jurídica promovidas por actores como el Banco Mundial, la AID o el BID y las impulsadas por las múltiples redes de organizaciones sociales y ONG de derechos humanos. En el campo específico de la reforma legal, como lo ha señalado Carothers (2001), mientras que los primeros tienden a centrarse en los objetivos del desarrollo económico y el fortalecimiento de la capacidad del Estado para combatir el crimen y la corrupción, los segundos privilegian las reformas que garanticen la protección eficaz de las libertades públicas y los derechos sociales. Ello explica por qué, aunque los dos sectores defiendan el fortalecimiento de la justicia y el Estado de derecho, sus propuestas sean claramente diferentes y choquen con frecuencia en la práctica, como lo muestra el enfrentamiento entre críticos y defensores del activismo judicial de la Corte Constitucional en relación con la protección de los derechos sociales en Colombia.

Dado el enfoque de esta obra en el sistema judicial y el relieve puesto en los programas que relacionan la reforma legal con el desarrollo económico, en lo que sigue me concentro en el primer grupo de actores. Como se verá enseguida, éstos han invertido la mayor cantidad de recursos en la reforma del aparato judicial con el fin de promover el desarrollo económico, ya sea por medio de reformas a las instituciones encargadas de proteger la propiedad privada y la seguridad contractual -por ejemplo, los proyectos sobre juzgados civiles y comerciales del Banco Mundial y el BID- o de programas de fortalecimiento a las instituciones a cargo de la penalización de los crímenes y la garantía del orden público - por ejemplo, la promoción de la introducción del sistema penal acusatorio en la región por parte de la AID-. Si bien estos programas tienen prioridades diversas y no son fruto de una planeación conjunta (Ginsburg, 1995; Carothers, 2001; y Jarquín y Carrillo, 1998), también poseen fundamentos teóricos, metodologías y temas afines 
que hacen posible agruparlos bajo la categoría de segunda generación de programas de derecho y desarrollo ${ }^{6}$.

\section{La concepción del derecho y el desarrollo en la segunda generación}

¿Cómo entienden los nuevos reformadores el derecho, el desarrollo y la relación entre uno y otro? Los programas de la nueva generación se fundan en una concepción más estrecha del desarrollo económico y en una versión más precisa del papel del derecho que las que inspiraban la primera generación. De acuerdo con el marco teórico e ideológico de estos programas -construido a lo largo de una serie de estudios de funcionarios y consultores de las agencias promotoras-, el desarrollo es entendido en términos de crecimiento económico y las reformas al derecho deben ser diseñadas de tal forma que apunten a dicho objetivo. Ibrahim Shihata, ex vicepresidente del Banco Mundial, explicó esta línea de pensamiento en los siguientes términos:

En América Latina y el Caribe, como en otras regiones, la experiencia ha demostrado con claridad el papel esencial del derecho en el desarrollo $y$, especialmente, la necesidad de tener un Estado de derecho y unas instituciones judiciales que funcionen adecuadamente. Esto es particularmente notorio en lo que tiene que ver con el sector privado, cuyo desarrollo depende en parte de la existencia del Estado de derecho. El Estado de derecho ofrece certeza y predecibilidad, genera costos de transacción más bajos y mayor acceso al capital [...] De hecho, la experiencia mundial confirma que para que sea posible un desarrollo rápido y sustentable es importante que se definan y protejan los derechos de propiedad, se hagan cumplir las obligaciones contractuales y se creen y se apliquen marcos regulatorios rigurosos (1995a: 13).
Como se aprecia en esta afirmación representativa, la segunda generación está basada en supuestos similares a los de la primera. Las dos comparten el núcleo de la teoría de la modernización, esto es, la visión lineal de la historia según la cual el camino hacia el crecimiento económico de los países 'atrasados' es la emulación de la experiencia de los países 'avanzados', en este caso mediante el transplante de las instituciones jurídicas de éstos a aquéllos. Los modelos que proponen comparten también componentes básicos: la defensa del legalismo liberal explicado anteriormente y del desarrollo económico logrado a través de la iniciativa privada en una economía de mercado. Finalmente, comparten la idea del lugar central del derecho en la tarea de construir un ambiente institucional propicio para el desarrollo.

Sin embargo, las dos generaciones difieren en aspectos relevantes. En primer lugar, la concepción del desarrollo de la segunda generación se centra claramente en el crecimiento económico y, por lo tanto, abandona la noción más comprehensiva de desarrollo de la primera generación, que incluía mayor igualdad y participación política. En otras palabras, mientras que uno de los elementos fundamentales de la justificación de la primera generación era contrarrestar la desigualdad en los países receptores, este fin parece ser para los actores de la segunda generación una consecuencia eventual del crecimiento económico.

Como lo ha afirmado María Dakolias, funcionaria del Banco Mundial encargada de los programas latinoamericanos de reforma judicial, modernizar las instituciones jurídicas es una prioridad, porque éstas "contribuyen a la eficiencia económica y estimulan el crecimiento que, a su vez, lleva a

Los trabajos recientes sobre el tema coinciden con la división entre las dos generaciones de derecho y desarrollo, así como con la identificación de la segunda generación con los programas liderados por actores como el Banco Mundial, el BID y la AID. Véanse Trubek (2006) y Kennedy (2006). 
la disminución de la pobreza" (1996: 71). En este raciocinio es evidente la creencia problemática según la cual la reducción de la pobreza depende fundamentalmente del crecimiento económico, antes que de una combinación de crecimiento y medidas redistributivas. Como es bien conocido, de acuerdo con esta idea del efecto de goteo (trickle-down economics), el crecimiento económico generará efectos secundarios que, en un largo plazo de duración indefinida, beneficiarán a los sectores más pobres.

En segundo lugar, el contraste entre los contextos económicos, políticos e ideológicos de la primera y la segunda generaciones marcan diferencias importantes entre una y otra. Mientras las reformas de los años sesenta surgieron en la fase final del auge del desarrollismo latinoamericano y el fordismo estadounidense -esto es, en tiempos en los cuales el "desarrollo hacia adentro", basado en la protección de la producción nacional y el papel activo del Estado, era parte del canon económico y político-, los nuevos proyectos de reforma legal emergieron en medio del proceso contemporáneo de globalización. De ahí que el tipo de desarrollo impulsado por los programas actuales esté fundado en la apertura comercial y la liberalización económica y en el papel protagónico del mercado antes que del Estado.

En este contexto de globalización, como lo ha explicado Jeffrey Sachs (1999), la reforma al derecho tiene dos objetivos precisos, que contrastan con los fines más indeterminados y ambiciosos de la primera generación. Dentro de cada país, su propósito central es crear las condiciones de estabilidad jurídica necesarias para atraer la inversión extranjera. En el escenario global, el objetivo es crear un marco regulatorio internacional que resuelva los conflictos entre empresas, individuos y Estados nacionales, que surgen de las actividades económicas transfronterizas que han proliferado en tiempos de globalización, desde el comercio de bienes y las inversiones de capital hasta el flujo creciente de inmigrantes. Desde esta visión, se trata de crear un Estado de derecho nacional e internacional que permita el funcionamiento fluido de los mercados.

Por estas razones, en vez de buscar que se transformen los cimientos de la cultura y la práctica jurídicas, como lo hicieron los reformadores de los años sesenta, los académicos y funcionarios de la nueva generación se han concentrado en un conjunto más limitado de instituciones y áreas del derecho. En efecto, el blanco privilegiado de las reformas ha sido el sistema judicial y, dentro de él, las instituciones encargadas específicamente de aplicar las regulaciones comerciales y penales. Al balance sumario de estas reformas está dedicada la siguiente sección.

\section{Los programas de reforma judicial en América Latina}

Hacer un recuento de los proyectos de reforma judicial emprendidos durante las dos últimas décadas en la región no es tarea fácil. La proliferación y falta de coordinación de los programas se refleja en la dispersión de los datos disponibles, que rara vez han sido compilados y comparados. Para contribuir a esta tarea de sistematización, en la Tabla 1 se sintetiza la información disponible en múltiples fuentes oficiales sobre los principales programas de reforma judicial financiados por Ios tres actores centrales de la segunda generación -la AID, el BID y el Banco Mundial-, así como los datos sobre los montos invertidos en dichos programas. 


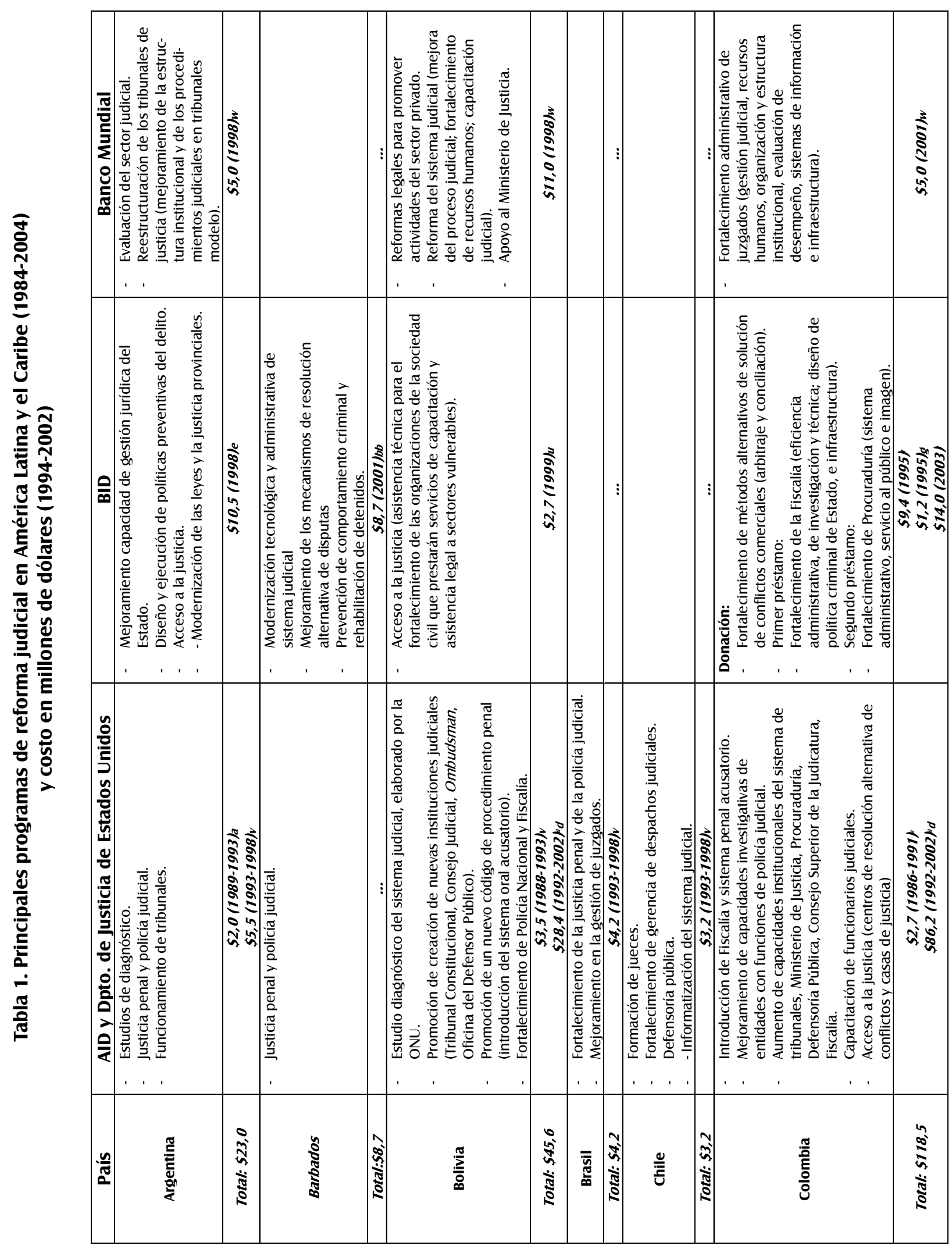




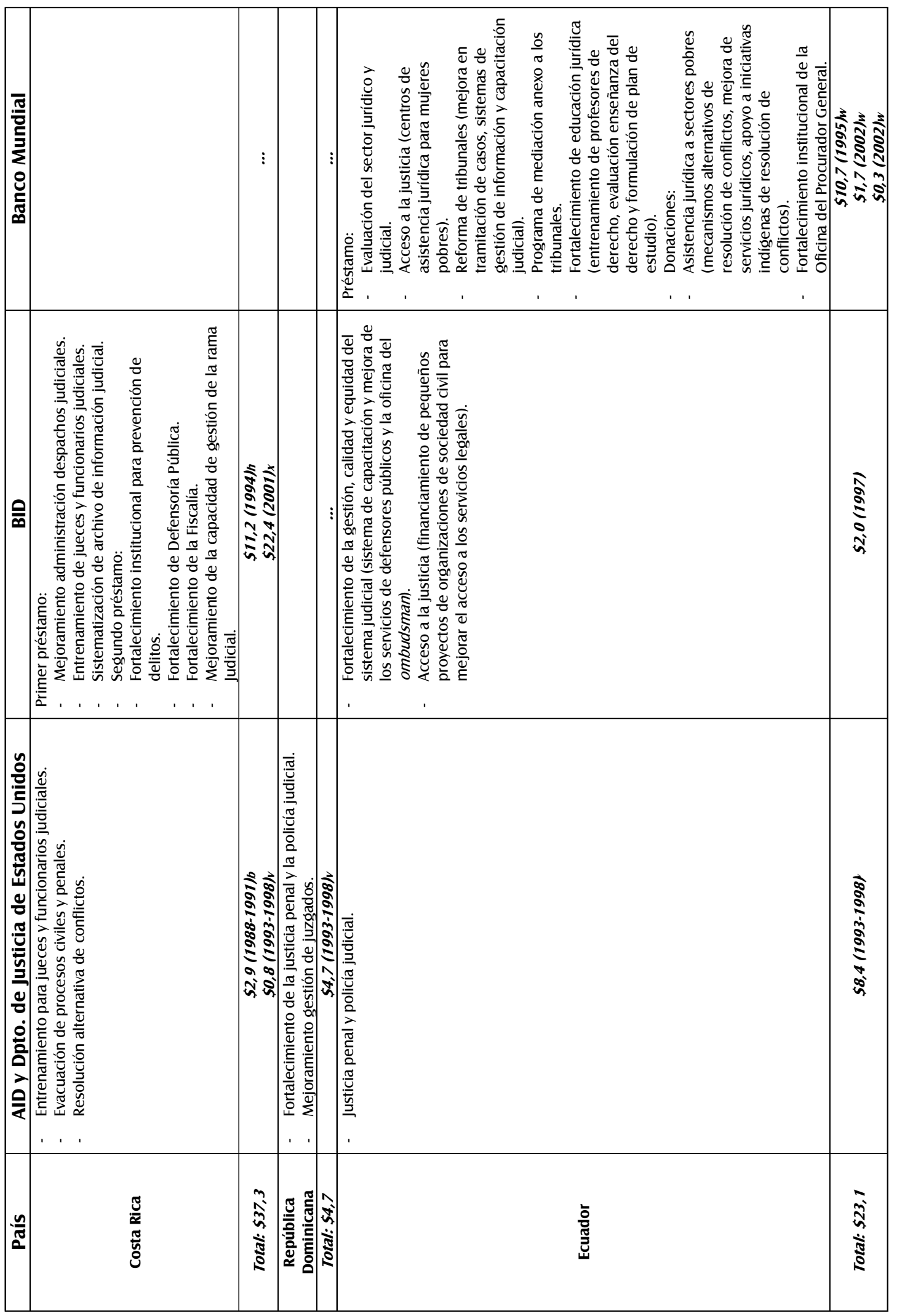




\begin{tabular}{|c|c|c|}
\hline País & AID y Dpto. de Justicia de Estados Unidos & \\
\hline El Salvador & 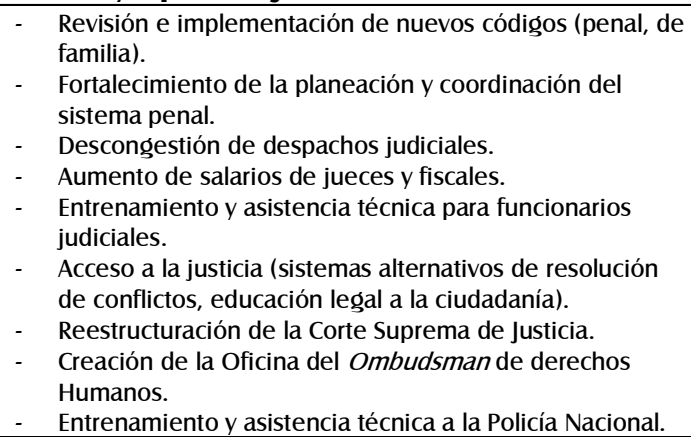 & \\
\hline Total: $\$ 120,1$ & $\begin{array}{c}\$ 13,7(1984-1992)_{b} \\
\$ 66,0(1992-2002)^{\prime} d\end{array}$ & \\
\hline Guatemala & $\begin{array}{l}\text { Mejoramiento del sistema penal (implementación de } \\
\text { nuevo Código Penal, apoyo a funcionarios judiciales } \\
\text { abogados y escuelas de derecho, creación de Defensoría } \\
\text { Pública, descentralización de la Fiscalía). } \\
\text { - Reestructuración y profesionalización de la Policía } \\
\text { Técnica Judicial (entrenamiento, asistencia técnica). } \\
\text { - } \quad \text { Acceso a la justicia (centros de justicia). } \\
\text { - Educación legal (revisión de currículo en facultad pública } \\
\text { de derecho, desarrollo de materiales pedagógicos). }\end{array}$ & $\begin{array}{ll}\text { - } & \text { For } \\
& \text { adr } \\
\text { - } & \text { Acc } \\
& \text { sis } \\
\text { me } & \\
\text { ofi } \\
\end{array}$ \\
\hline Total: $\$ 101,6$ & $\begin{array}{c}\$ 6,1(1987-1993)_{b} \\
\$ 37,4(1992-2002)^{\prime} d\end{array}$ & \\
\hline Haití & $\begin{array}{l}\text { - } \quad \text { Apoyo a monitores policiales internacionales tras golpe } \\
\text { de Estado de } 1991 . \\
\text { - } \quad \text { Desarrollo y apoyo de una Policía Nacional Civil. } \\
\text { - } \quad \text { Apoyo al sistema de justicia penal. }\end{array}$ & \\
\hline Total: $\$ 137,0$ & $\$ 137,0(1993-1998)_{V}$ & \\
\hline
\end{tabular}




\begin{tabular}{|c|c|c|}
\hline País & AID y Dpto. de Justicia de Estados Unidos & \\
\hline Honduras & $\begin{array}{ll}- & \text { Mejoramiento del sistema penal (elaboración e } \\
\text { implementación de nuevo código, apoyo a tribunales, } \\
\text { fiscales y defensores públicos). } \\
\text { - }\end{array}$ & $\begin{array}{l}\text { Primer } \\
-\quad \text { Mo } \\
\text { de } \\
\text { fur } \\
\text { jur } \\
\text { pro } \\
\text { do } \\
\text { - For } \\
\text { ad } \\
\text { juc } \\
\text { Sol } \\
\text { (ar }\end{array}$ \\
\hline Total: $\$ 62,3$ & $\begin{array}{l}\$ 15,8(1987-1994)_{a} \\
\$ 7,8(1993-1998)_{v}\end{array}$ & \\
\hline Jamaica & $\begin{array}{ll}\text { - } & \text { Fortalecimiento justicia penal y Policía Judicial. } \\
\text { - } & \text { Mejoramiento gestión de juzgados. }\end{array}$ & \\
\hline Total: \$5,1 & $\begin{array}{r}\$ 2,8(1986-1990)_{C} \\
\$ 2,3(1993-1998)_{V}\end{array}$ & \\
\hline México & $\begin{array}{ll}\text { - } & \text { Fortalecimiento justicia penal y Policía Judicial. } \\
\text { - } & \text { Mejoramiento gestión de juzgados. }\end{array}$ & \\
\hline Total: $\$ 7,3$ & $\$ 7,3(1993-1998)_{V}$ & \\
\hline Nicaragua & $\begin{array}{l}\text { Modernización del sistema penal (apoyo a } \\
\text { implementación de nuevo código penal). } \\
\text { - Consolidación de organismos con funciones de policía } \\
\text { judicial. }\end{array}$ & $\begin{array}{l}\text { Donac } \\
-\quad \text { For } \\
\text { pré } \\
-\quad \text { Pré }\end{array}$ \\
\hline Total: $\$ 26,7$ & dז' $\$ 13,0(1992-2002)$ & \\
\hline
\end{tabular}




\begin{tabular}{|c|c|c|}
\hline País & AID y Dpto. de Justicia de Estados Unidos & \\
\hline Panamá & 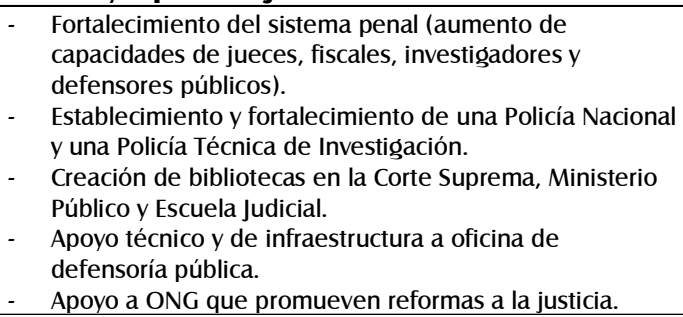 & $\begin{array}{ll}- & \text { Mej } \\
\text { de } j\end{array}$ \\
\hline Total:\$44,0 & $\begin{array}{r}\$ 13,1(1990-1995)_{d} \\
\$ 12,0(1993-1998)_{V}\end{array}$ & \\
\hline Paraguay & $\begin{array}{ll} & \text { Fortalecimiento justicia penal y Policía Judicial. } \\
\text { - } & \text { Mejoramiento gestión de juzgados. }\end{array}$ & $\begin{array}{l}\text { - } \\
\text { de } \\
\text { info }\end{array}$ \\
\hline Total: $\$ 25,7$ & $\$ 3,3(1993-1998)_{V}$ & \\
\hline Perú & $\begin{array}{ll}\text { - } & \text { Fortalecimiento de la justicia penal y la policía judicial. } \\
\text { - } & \text { Mejoramiento gestión de juzgados. }\end{array}$ & $\begin{array}{lr}- & \text { Solı } \\
- & \text { ACC } \\
\end{array}$ \\
\hline Total: $\$ 37,9$ & $\begin{array}{c}\$ 2,8(1986-1991)^{\prime} \\
\$ 13,2(1992-2002)^{\prime} d \\
\end{array}$ & \\
\hline Uruguay & $\begin{array}{ll}\text { - } & \text { Administración de despachos judiciales. } \\
\text { - } & \text { Entrenamiento de funcionarios judiciales. } \\
\text { - } & \text { Legislación comercial. }\end{array}$ & $\begin{array}{l}\text { Mej } \\
\text { y fo } \\
\text { fort }\end{array}$ \\
\hline Total: $\$ \mathbf{8}, 3$ & $\begin{array}{l}\$ 0,8(1990-1993)_{a} \\
\$ 1,4(1993-1998)_{v}\end{array}$ & \\
\hline \multicolumn{2}{|r|}{$\begin{array}{ll}\text { - } & \text { Fortalecimiento de la justicia penal y } \\
\text { judicial. } \\
\text { - } \quad \text { Mejoramiento gestión de juzgados. }\end{array}$} & $\begin{array}{ll}- & M \\
- & \text { Fo } \\
& (\mathrm{m} \\
& \mathrm{m}\end{array}$ \\
\hline Total: $\$ 118,1$ & $\begin{array}{c}\$ 3,7(1993-1998)_{v} \\
\$ 4,7(1997)_{m}\end{array}$ & \\
\hline
\end{tabular}




\section{Fuentes para la información del cuadro}

(a) Blair, Harry y Hansen, Gary. 1994. Weighing in on the scales of justice. Strategic approach for donorsupported rule of law programs. USAID Program and Operations Assessment Report No. 7. Washington D.C.: USAID.

(b) United States General Accounting Office. 1993. Foreign assistance. Promoting judicial reform to strengthen democracies. Report to congressional request. GAO/NSIAD-93-149. Washington: GAO.

(c) Washington Office on Latin America. 1990. Elusive justice. The US administration of justice program in Latin America. Washington: WOLA, p. 14.

(d) United States General Accounting Office. 1992. Aid to Panama. Improving the criminal justice system. Report to the Chairman, Subcommittee on Foreign Operations, Committee of Appropriations, US Senate. GAO/NSIAD-92-147. Washington: GAO.

(e) BID, Comunicado de prensa, febrero 11, 1998. "BID, Argentina firman US\$10,5 millones para reforma de justicia. Financiará protección jurídica, políticas preventivas y de acceso a la justicia". Project AR-0124. "Program in Support of Judicial System Reform", Operation No. 1082/OC-AR.

(f) BID, Comunicado de prensa, febrero 12, 1996. "BID, Colombia firman US\$9,4 millones para reforma judicial". Project 909/OC-CO.

(g) No reembolsable. BID, Comunicado de prensa, mayo 30, 1995. "El Fondo Multilateral de Inversiones aprueba US\$1,220,000 para fortalecer métodos alternativos de solución de controversias en Colombia".

(h) BID, Press release, enero 25, 1995. "IDB approves its first loan for modernization of justice. \$11.2 million to support judicial reform in Costa Rica". Project CR0073. "Program for the Modernization of the Administration of Justice", Operation No. 859/OC-CR.

(j) BID, Comunicado de prensa, septiembre 3, 1997. “BID aprueba US\$2 millones para reforma judicial en Ecuador. Programa fortalecerá gestión, calidad y equidad de los servicios".

(k) BID, Comunicado de prensa, marzo 13, 1996. "BID aprueba US\$22,2 millones para la reforma judicial en
El Salvador. Modernización de tribunales, reducción de la delincuencia juvenil”. Project ES-0090. "Program to Support the Justice System", Operation No. 919/ OC-ES; 920/OC-ES.

(I) BID, Press release, Agosto 13, 1998. "BID aprueba US\$25 millones para reforma de justicia en Guatemala". Project GU-0092. "Program in Support of Judicial Reform".

(m) Lawyers Committee on Human Rights. 1998. Selected World Bank, IDB and ADB judicial and/or legal reform projects. New York: LCHR.

(n) BID, Comunicado de prensa, marzo 18, 1996. "BID aprueba US\$8,7 millones para reforma judicial en Honduras. Programa mejorará confiabilidad y equidad del sistema legal". Project HO-0109. "Program to Modernize the Administration of Justice", Operation No. $974 /$ SF-HO.

(o) BID, Comunicado de prensa, agosto 7, 1996. “BID aprueba US\$1,7 millones para reformas del Estado en Nicaragua. Fortalecimiento de la Asamblea Nacional, reforma del sistema de justicia".

(p) BID, Project PN-0086. "Program to Improve the Administration of Justice Stage One", Operation 1099/ OC-PN.

(q) BID, Press release, noviembre 25, 1998.

(r) BID, Comunicado de prensa, noviembre 25, 1997. "BID aprueba US\$20 millones para mejorar acceso a la justicia en Perú. Mayor equidad judicial para sectores geográficos y sociales hasta ahora marginados". IDB Project PE-0126. "Improving Access to the Justice System", Operation 1061/OC-PE.

(s) World Bank, Press release, octubre 22, 1998.

(t) BID, Press release, abril 30, 2003. “IDB approves $\$ 14$ million to strengthen Colombia's public sector oversight agency. Procuraduría General de la Nación will be better equipped to investigate and sanction cases of public misconduct". Project CO-0258. "Program to Strengthen the Office of the AttorneyGeneral of the Nation".

(u) BID, Press release, junio 30, 1999. “IDB approves $\$ 2.7$ million for Bolivian civil society organizations to assist 
vulnerable groups gain access to justice". Project BO-0177. "Program for Civil Society and Access to Justice", Operation No. 1038/SF-BO.

(v) United States General Accounting Office. 1999. Foreign assistance. Rule of law funding worldwide for fiscal years 1993-1998. GAO/ NSIAD-99-158. Washington: GAO.

(w) World Bank. 2004. Initiatives in legal and judicial reform, 2004 Edition. Legal Vice Presidency World Bank. Washington: The World Bank.

(x) BID, Press release, diciembre 6, 2001. "IDB approves \$22.4 million for modernization of justice in Costa Rica". Project CR-0141 "Second Phase of the Program for the Administration of Justice".

(y) BID, Press release, noviembre 20, 2002. "IDB approves $\$ 30$ million soft loan for justice administration in Honduras". Project HO-0210. "Program to Support Modernization of the Administration of Justice, Stage II".

(z) BID, Press release, marzo 1, 2001. “IDB approves $\$ 12$ million to support judicial reform and modernization in Nicaragua". Project NI-0081.

(aa) BID, Press release, noviembre 1, 2000. "IDB approves $\$ 6.1$ million to improve judicial services in Uruguay". Project UR-0122.

(bb) BID, Press release, Agosto 1, 2001. "IDB approves $\$ 8,750,000$ to modernize justice system in Barbados". Project BA-0055. "Administration of Justice Program".

(cc) BID, Press release, noviembre 15, 2001. “IDB approves $\$ 75$ million to support reform of criminal justice system in Venezuela". Project VE0057. "Support for Reform of the Criminal Justice System".

(dd) United States General Accounting Office. 2003. Foreign assistance. U.S. democracy programs in six Latin American countries have yielded modest results. GAO-03-358. Washington: GAO.
En vista de los objetivos específicos planteadas al inicio, no es éste el lugar para comentar de forma exhaustiva los programas y cifras sintetizados en la Tabla 1. En lugar de ello, importa resaltar las tendencias generales y concentrarse en lo que los datos revelan sobre las conexiones entre los proyectos nacionales de reforma judicial y las similitudes y diferencias de éstos en relación con la primera generación de derecho y desarrollo. Con este fin, conviene empezar por identificar los temas medulares que pueden ser detectados en medio de la diversidad de programas reflejada en la tabla.

Los principales proyectos pueden ser clasificados en cinco grandes temas. Primero, una parte considerable de los programas ha apuntado al mejoramiento de la administración de los despachos judiciales y a la reducción de los inventarios de procesos pendientes. Las demoras alarmantes y la congestión, que caracterizan el funcionamiento de los juzgados y las cortes latinoamericanas, tienen sus orígenes en serias deficiencias tanto en la infraestructura básica (por ejemplo, oficinas y equipos obsoletos) como en sistemas inadecuados de administración de la carga de trabajo. Por lo tanto, los programas de este tipo han hecho hincapié en la actualización de la infraestructura y los métodos de administración, así como en el uso de mecanismos alternativos de resolución de conflictos y reformas a los códigos de procedimiento para eliminar formalidades que agravan las demoras.

Como se aprecia en la tabla, éste ha sido el objetivo central de los programas financiados por el BID y el Banco Mundial en la región. Dado el propósito de estas dos entidades de incentivar la inversión privada, el sector privilegiado de estas reformas ha sido la justicia civil y comercial, encargada de garantizar la seguridad de los contratos y la protección de los derechos de propiedad. Algunas ilustraciones prominentes de este tipo de programas de fortalecimiento gerencial y de infraestructura han sido los préstamos del Banco Mundial a Venezuela y Argentina, a mediados de los años noventa, para la implementación de juzgados modelo, y los préstamos otorgados por el BID y el Banco 
Mundial a Ecuador, Bolivia, Honduras y Uruguay para el mejoramiento de la infraestructura y la tecnología disponible para el cumplimiento de las labores judiciales.

Segundo, una parte importante de los proyectos -en particular los financiados por la AID- intenta fortalecer los juzgados y los tribunales penales $y$ mejorar las técnicas de investigación de los delitos. De hecho, en la tabla se aprecia que a este tipo de programas se han destinado las inversiones más cuantiosas de la nueva fase de reformas judiciales. En efecto, el monto de las principales transferencias de la AID y del Departamento de Estado de Estados Unidos para la reforma legal (536 millones de dólares), que están representadas en su mayor parte por estos proyectos, supera el monto combinado de los préstamos y donaciones que el BID y el Banco Mundial ha dedicado a los programas más destacados de la segunda generación (325 y 120 millones de dólares, respectivamente). Como se observa en la tabla, varios programas de este tipo han incluido la promoción del transplante del sistema penal acusatorio de corte estadounidense a los países receptores. Este es el caso, por ejemplo, de Bolivia, Colombia (que será comentado con detalle más adelante) y Chile (que fue financiado por fuentes diversas).

Tercero, varios de los principales proyectos tienen un componente de promoción de la independencia del poder judicial. El principal mecanismo utilizado por las agencias financiadoras para impulsar este objetivo ha sido la introducción de nuevas instituciones -en especial consejos superiores de la judicatura-, encargadas de administrar de forma autónoma el presupuesto y la organización del sistema judicial. Así sucedió, por ejemplo, en los proyectos emprendidos en Guatemala, El Salvador, Venezuela, Bolivia, Paraguay y Colombia. De manera similar, se han destinado fondos para impulsar reformas legislativas y administrativas que buscan promover sistemas de eva- luación y nombramiento independientes y meritocráticos en el poder judicial. Ejemplos prominentes de este tipo de iniciativas han sido los programas de fortalecimiento de la carrera judicial en Guatemala y Ecuador, financiados por el BID y el Banco Mundial.

Cuarto, varios proyectos contienen un elemento educativo pero, a diferencia de la primera generación, éste apunta principalmente al entrenamiento de jueces y funcionarios judiciales, antes que de profesores y estudiantes de derecho. Así lo muestran, por ejemplo, los programas de formación de jueces financiados por el BID en Costa Rica y los programas de formación de jueces y fiscales patrocinados por la AID en Chile y Colombia. La excepción a esta tendencia es el programa del Banco Mundial en Ecuador, que tuvo un componente importante de entrenamiento de profesores de derecho y evaluación de los currículos de las facultades de derecho.

Finalmente, un número creciente de iniciativas busca mejorar el acceso a la justicia de la ciudadanía, en general (por ejemplo, mediante la promoción de mecanismos informales de solución de conflictos, como la mediación), y de sectores marginados de la población, en particular (por ejemplo, por medio de programas de asesoría jurídica popular o centros de conciliación y mediación en zonas marginales de las grandes ciudades). Esta importante tendencia es notoria, por ejemplo, en los proyectos que llevan el sistema judicial a los sectores urbanos y rurales marginados, como las llamadas casas de justicia e instituciones similares en Perú, Nicaragua, Ecuador, Colombia y Guatemala.

Un signo igualmente alentador son otros proyectos que apuntan en la misma dirección, al promover el fortalecimiento de las instituciones estatales encargadas de la defensa de los derechos de la ciudadanía, en general, y de las poblaciones vulnerables, en particular. Ejemplos de ello 
son los programas de creación o consolidación de las defensorías públicas y de la institución del ombudsman, como los impulsados en Bolivia, Chile, Honduras, Panamá, Guatemala y Costa Rica.

Más allá de identificar los ejes principales de las reformas judiciales, iqué conclusiones se pueden extraer de la síntesis de la segunda generación recogida en la Tabla 1? A mi manera de ver, las conclusiones más relevantes son las siguientes:

La reforma judicial es un proyecto regional; sin embargo, existen importantes diferencias en la participación de los países en los programas. La primera parte de esta conclusión muestra lo que escapa a la vista de la mayoría de estudios existentes sobre el tema, que se concentran en un país específico: existen conexiones claras entre las iniciativas emprendidas a lo largo y ancho de América Latina, de tal forma que es posible hablar de una verdadera ola regional de reformas judiciales desde mediados de los años ochenta. Como lo muestra la tabla, los promotores y los temas de los proyectos son comunes a los diferentes casos nacionales, y la gran mayoría de países de la región participa en ellos. Si se tiene en cuenta que reformas con contenidos y actores similares han proliferado en el mismo período en otras regiones del antiguo Tercer Mundoespecialmente Europa Oriental y Asia-, se concluye que la reforma judicial es un proyecto de escala global (véase Carothers, 2006b).

Esto no oculta el hecho de igual forma importante de que el grado de participación de algunos países es mucho mayor que el de otros. Es especialmente llamativo que mientras países que tienen algunas de las economías más pequeñas de la región (como El Salvador, Nicaragua y Guatemala) hayan sido recipientes de algunas de las financiaciones más altas para proyectos de este tipo, los países con las economías más poderosas (Brasil y México) no se hayan embarcado en ambiciosas reformas financiadas por el BID, el
Banco Mundial o la AID. El caso de Colombia, donde se ha emprendido el proyecto de reforma más prolongado (financiado por la AID), y uno de los más caros de la segunda generación, merece un comentario detallado que será hecho en la siguiente sección.

La ola contemporánea de reformas judiciales es un proyecto mucho más ambicioso y costoso que los programas de la primera generación de derecho y desarrollo. A la luz de los datos de la Tabla 1, el anuncio prematuro del deceso de las ideas y programas de derecho y desarrollo resulta aún más paradójico. En efecto, en lugar de disminuir tras el fracaso de la primera generación, las sumas invertidas en reformas jurídicas en las últimas dos décadas se han disparado a niveles que los financiadores de los programas de los años sesenta nunca habrían estado dispuestos a in vertir. Mientras el total de los fondos dedicados a las reformas de la enseñanza del derecho hace cuatro décadas se acercó a los cinco millones de dólares (Gardner, 1980), los dineros destinados a los principales programas de la segunda generación, hasta 2004, llegan casi a los mil millones de dólares. Incluso cuando esta última cifra se ajusta por inflación, la escala mucho más modesta de los programas pioneros de derecho y desarrollo es incomparable con la gran escala de la inversión reciente en reformas jurídicas.

La misma diferencia se aprecia en la ambición y variedad de los programas. Mientras los de la primera ola estaban centrados en la transformación de las facultades de derecho, la segunda incluye instituciones tan diversas como los juzgados, la policía, las fiscalías, los consejos superiores de la judicatura, los sistemas de arbitraje y conciliación, las casas de justicia y las altas cortes. En suma, además de regional y global, la reforma judicial es un proyecto de envergadura e inversiones muy considerables, que hacen muy probable su continuación en los años venideros. 
Existen diferencias importantes en el grado de participación de los financiadores de la segunda generación. Los datos de la Tabla 1 contrastan con la impresión común en los círculos especializados de que la reforma judicial es impulsada por igual por los tres principales patrocinadores. Si atendemos a las sumas invertidas, es claro que el motor de la segunda generación es la cooperación internacional estadounidense, a través de la AID y el Departamento de Justicia. La banca multilateral -que tiende a ser el objeto de la mayor parte de los estudios y críticas sobre el tema- tiene una participación importante, pero distante de los montos comprometidos directamente por Estados Unidos. De ahí la importancia del estudio de los programas de la AID, como el que se hace más adelante para el caso colombiano, para entender y evaluar la segunda generación de derecho y desarrollo.

Aunque los objetivos privilegiados continúan siendo el fortalecimiento de la justicia penal y comercial, el acceso a la justicia y los sistemas de defensa de derechos ciudadanos han ganado importancia en la agenda reformadora. A lo largo de este capítulo, he sostenido que los programas de reforma judicial de las dos últimas décadas han tenido una visión altamente selectiva de las garantías del Estado de derecho. De acuerdo con esta concepción minimalista o "de baja intensidad" del Estado de derecho, la función principal del derecho y los jueces es garantizar los derechos de propiedad y la paz pública. Por esta razón, desde este punto de vista, la reforma judicial debe dar relieve a la solución expedita de conflictos comerciales y el castigo oportuno de los delitos.

Los datos recogidos en la Tabla 1 corroboran esta tesis y muestran una cierta división informal del trabajo entre las tres agencias financiadoras. En efecto, mientras la AID dedica la mayor parte de sus recursos al fortalecimiento de la justicia pe- nal, el BID y el Banco Mundial dirigen buena parte de sus préstamos y donaciones al mejoramiento de los juzgados civiles y comerciales y a la consolidación de sistemas alternativos de solución de conflictos de este tipo (por ejemplo, el arbitraje y la conciliación extrajudicial).

Sin embargo, como se mencionó, la tabla muestra también un número importante de proyectos destinados a mejorar la equidad y accesibilidad del sistema judicial, que van desde la construcción de casas de justicia hasta programas piloto de defensa de derechos de poblaciones vulnerables, pasando por el establecimiento de un sistema de abogados penales de oficio para acusados sin medios para contratar un defensor privado.

El alentador ascenso de estos temas en la agenda reformadora, unido a la creciente preocupación de las agencias financiadoras por involucrar a la población civil en la ejecución de los programas, ha llevado a algunos autores como Trubek (2006) a hablar del surgimiento de una nueva fase de la segunda generación de derecho y desarroIlo. Esta etapa estaría marcada por una aproximación más participativa y comprehensiva a las reformas, una posición menos incondicional sobre la bondad de los transplantes jurídicos, una visión de más largo plazo y una mayor atención a problemas de equidad. En suma, en contraste con la etapa inicial de la segunda generación, que repitió muchos de los errores de la primera, esta nueva fase estaría encaminándose hacia una aproximación más promisoria a la reforma del derecho (Trubek, 2006). En este diagnóstico coinciden las propias agendas financiadoras, que, como lo muestran los documentos recientes del Banco Mundial sobre el tema, buscan distanciarse explícitamente tanto de la primera generación de derecho y desarrollo de los años sesenta como de la fase inicial de los programas de ajuste estructural de la década de los ochenta (Banco Mundial, 2002; y Dakolias, 2001). 
En mi opinión, es aún temprano para saber si los cambios de contenido y metodología de las reformas judiciales tienen la profundidad y la duración necesarias para representar una nueva aproximación al derecho y el desarrollo, o si, por el contrario, son modificaciones relativamente menores al enfoque convencional. Es importante anotar, además, que el cambio en el lenguaje utilizado por los reformadores jurídicos hace parte de un giro detectable en el discurso general sobre el desarrollo económico que las agencias involucradas han adoptado desde la segunda mitad de los años noventa, como respuesta a los resultados desalentadores y las críticas de gobiernos y ONG de la región a los programas de ajuste estructural.

Como lo hemos mostrado en otro lugar (Rodríguez Garavito, 2005), este giro se concreta en un paradigma de regulación que, bajo el nombre de gobernanza (governance), le da relieve a la participación selectiva de sectores de la sociedad civil en la producción e implementación de políticas públicas, incluidas las reformas judiciales. Sin embargo, según lo muestra con agudeza Santos (2005), los elementos de participación $y$ equidad tienden a ser subordinados a los fines y mecanismos centrales de dicha aproximación, que continúan estando centrados en el fortalecimiento del mercado.

El rumbo que tomen los programas de derecho y desarrollo - hacia la continuación de una concepción minimalista del Estado de derecho o hacia una concepción más robusta y equitativa del sistema judicial y la democracia- está todavía por definirse. Antes que aventurarse a pronosticar el futuro de la reforma judicial, la labor analítica inmediata consiste en documentar y evaluar el recorrido hecho por la segunda generación. Esta fue la labor emprendida en la presente sección, mediante la síntesis y el comentario del panorama general de las reformas judiciales en América Latina durante los últimos veinte años. Sin em- bargo, para entender y evaluar a cabalidad la segunda generación es necesario complementar el análisis del bosque de las reformas con el estudio de los árboles concretos de los programas nacionales. Este es el objetivo de la siguiente sección, en la que el análisis va a los detalles de una reforma concreta, esto es, el programa más ambicioso y costoso de la segunda generación, emprendido en Colombia con el patrocinio de la AID.

\section{Un estudio de caso: las reformas a la administración de justicia financiadas por la AID en Colombia}

La participación activa de la AID en la reforma del poder judicial colombiano ha pasado por tres fases (Arenas y Gómez, 2000; y Santos, 2001). La primera (entre 1986 y 1991) fue de tipo exploratorio, y consistió en un principio en la financiación de varios proyectos de investigación sobre congestión y mora judiciales y sobre mecanismos de resolución alternativa de conflictos. En este período, la AID también patrocinó algunos esfuerzos iniciales para introducir innovaciones tecnológicas para mejorar el sistema de información judicial, así como varios programas de entrenamiento para jueces y la creación de una biblioteca oficial del poder judicial. Los recursos que la AID destinó a esta primera fase sumaron 3.264.000 dólares y fueron administrados por la Fundación para la Educación Superior (FES) (Rondón, 1998). Tanto la AID como la FES concibieron estos esfuerzos exploratorios como el prefacio a un programa ambicioso de reforma judicial que llamaron Programa para la Modernización de la Administración de Justicia.

Al final de este período, la AID comenzó a trabajar en el proyecto que pasaría a ser el centro de sus actividades en Colombia, esto es, la promoción de un sistema penal de tipo acusatorio, basado en la creación de la Fiscalía General de la Nación, e inspirado en el modelo de investiga- 
ción penal de Estados Unidos. La ocasión propicia para este proyecto fue la Asamblea Constituyente de 1991. La AID intentó influir en la creación y el diseño de la Fiscalía mediante el cabildeo que ejerció y las propuestas que presentó en las comisiones encargadas del tema de la administración de justicia en la Asamblea.

De acuerdo con la AID y con algunos sectores de la comunidad jurídica colombiana, el sistema acusatorio era más adecuado que el inquisitivo, que Colombia había heredado del sistema continental en el siglo XIX, y en el que los jueces no sólo dirigían la investigación, sino también dictaban sentencia. Tener fiscales especializados, según este punto de vista, traería mayor eficiencia en la investigación de delitos y garantizaría la protección de los derechos procesales del acusado durante el juicio. El objetivo fundamental de los proponentes del sistema acusatorio era disminuir la alarmante tasa de impunidad en Colombia ${ }^{7}$.

Los resultados de los debates en la Asamblea Constituyente sobre la Fiscalía ilustran el proceso de transplante de instituciones jurídicas alentado por los organismos financiadores de reformas judiciales en América Latina. Dentro del modelo estadounidense propuesto por la AID, el papel de los fiscales, que pertenecen a la rama Ejecutiva, se limita a la investigación de los delitos y a la acusación ante el juez competente. El juez, no el fiscal, decide si el acusado debe ser liberado o sigue detenido durante la investigación. Por el contrario, en el sistema inquisitivo que existió en Colombia antes de 1991 la investigación era una labor del poder judicial, en cuanto los jueces tenían competencia sobre todos los aspectos del proceso penal. Ellos dirigían la investigación, decidían acerca de la libertad del acusado y eventualmente lo condenaban o absolvían.
El choque entre los dos modelos en la Asamblea Constituyente dio lugar a intensos debates. Por un lado, los defensores del modelo estadounidense hacían hincapié en el potencial de éste para mejorar la investigación de los delitos. Por el otro, los críticos del transplante señalaban el peligro que implicaba para la independencia judicial. Dado que la independencia judicial había sido en Colombia la piedra angular del control de los abusos cometidos por el Ejecutivo y el Legislativo $-y$ dado que estaban frescos aún los recuerdos de los efectos perversos de los sistemas penales politizados creados por regímenes autoritarios en varios países latinoamericanos- tanto juristas tradicionales como defensores de derechos humanos se opusieron al transplante incondicional del modelo estadounidense.

El resultado del debate fue una solución intermedia plasmada en un sistema singular. Siguiendo el modelo por el que se inclinaba la AID, la Constitución de 1991 introdujo una nueva institución poderosa, la Fiscalía, cuya función central sería investigar delitos. Sin embargo, para evitar el peligro de un sistema penal politizado, la Constitución incorporó la Fiscalía al poder Judicial y dio a los fiscales funciones judiciales, como decidir sobre la libertad de las personas que son investigadas. De esta forma, la interacción entre una propuesta de transplante jurídico y la cultura y la comunidad jurídicas locales dio lugar a un híbrido singular, a una suerte de fiscal/semijuez que a primera vista se parece más al juez del viejo sistema inquisitivo que al fiscal del sistema acusatorio. En la práctica, esta figura híbrida tuvo efectos positivos moderados en la investigación de los delitos, aunque también dio lugar a numerosas quejas por la violación de derechos humanos por parte de poderosos fiscales dotados de funciones judiciales.

De acuerdo con algunos cálculos, a comienzos de los años noventa sólo $5 \%$ de los crímenes cometidos en el país eran investigados y castigados (Rubio, 2001). Sin embargo, éste y otros índices de impunidad han sido objeto de diversas críticas metodológicas, de manera tal que no existe certeza sobre el número de crímenes no penalizados en el país. 
La entrada en vigencia de las transformaciones jurídicas y políticas producidas por la Constitución de 1991 coincidió con la época en la que la AID inició la segunda fase del Programa para la Modernización de la Administración de Justicia (Arenas y Gómez, 2000; y Santos, 2001). Esta fase, que se extendió de 1992 a 1996, estuvo dominada por el interés de la administración de George Bush (padre) por promover la llamada guerra contra las drogas en los países productores, especialmente en Perú, Bolivia y Colombia.

Con este fin, en febrero de 1990 los gobiernos de Estados Unidos y Colombia firmaron un acuerdo en la Cumbre de San Antonio, por medio del cual el primero prometió destinar 36 millones de dólares -que serían administrados por la AID- a mejorar la capacidad del sistema judicial colombiano para investigar y castigar delitos. Este acuerdo convirtió a Colombia en el mayor destinatario de fondos de la AID en América Latina. Además, la suma involucrada constituyó cerca del $50 \%$ de los fondos internacionales destinados al sector judicial en Colombia en los años noventa (García, 1995).

Durante la segunda fase, la AID continuó asociada con la FES, la fundación colombiana que había participado en el diseño y la ejecución de la primera fase. Además, conforme al acuerdo intergubernamental que destinó los fondos mencionados para la reforma judicial, los recursos deberían ser asignados por un comité ejecutivo conformado por representantes de la AID y del Ministerio de Justicia, el Consejo Superior de la Judicatura, la Fiscalía y la Corte Suprema. El comité debía evaluar las peticiones de financiación presentadas por las instituciones que las integraban, por otras entidades gubernamentales y por universidades y ONG dedicadas a hacer estudios y formular políticas sobre el sistema judicial.
Dentro del comité surgió un intenso debate que ilustra bien el choque entre las perspectivas y los intereses de la agencia donante en Estados Unidos, por un lado, y sus representantes y las autoridades locales en el país receptor, por el otro, que constituye una dificultad común de los programas de reforma judicial. Como lo sostuvo Luis Roa -vicepresidente administrativo de la AID en Colombia, quien fue uno de los miembros del comité- en una entrevista en $1996^{\circ}$, aunque los miembros de la AID en Colombia planeaban al comienzo de la segunda fase fortalecer el sistema penal en general, la prioridad en Washington era más estrecha, esto es, lograr efectos inmediatos y directos en relación con el castigo a narcotraficantes. Esto dio lugar a una controversia persistente acerca de la evaluación de los resultados, que a su vez impidió el diálogo fluido entre la AID en Washington y las instituciones y organizaciones colombianas que hacían parte del proyecto.

Siguiendo la filosofía de la segunda fase, y a pesar de los desacuerdos mencionados, la asignación de recursos entre 1992 y 1995 dio clara prioridad al mejoramiento de la investigación de delitos. De hecho, la Fiscalía recibió cerca del 35\% de los fondos que fueron entregados en este período (García, 1995; y Rondón, 1998). Se hizo hincapié en el entrenamiento de nuevos fiscales, en el uso de técnicas de investigación avanzadas, en la protección de fiscales y jueces y en la construcción de la infraestructura de la naciente Fiscalía. De hecho, como lo explicó Roa en la entrevista mencionada, los fondos de la AID fueron decisivos para que la Fiscalía comenzara a funcionar, dado que la Asamblea Constituyente no previó la forma como serían financiadas las nuevas instituciones. Sin embargo, una parte considerable de los fondos fue destinada a proyectos variados, como una campaña en los medios de comunica-

Entrevista realizada por Gabriel Gómez, Bogotá, diciembre de 1996. 
ción para mejorar la imagen del sistema judicial, un programa para la reducción de la congestión en los juzgados y un plan para la consolidación de un sistema eficiente de estadísticas judiciales (García, 1995; y Rondón, 1998).

Hacia el final de la segunda fase (1995-1996), la percepción de la AID acerca de los fines del programa comenzó a enfocarse hacia la perspectiva defendida unos años atrás por varias de las instituciones colombianas representadas en el comité ejecutivo. Como se explicó en párrafos anteriores, dicha perspectiva concebía los programas en términos amplios, esto es, como formas de mejorar el sistema judicial como un todo, antes que un sector específico. Igualmente, ponía de presente la necesidad de enfrentar las deficiencias no sólo de la 'oferta' de justicia (esto es, la capacidad de los juzgados y tribunales para decidir los casos justa y eficientemente), sino también las que aquejaban a la 'demanda' de justicia (esto es, los múltiples obstáculos que impiden a la mayoría de los ciudadanos tener acceso efectivo a la justicia).

Como Eduardo Aldana, antiguo director de la FES, lo explicó en una entrevista ${ }^{9}$, el desarrollo de la segunda fase llevó a la FES a la conclusión de que el proyecto estaba dando una importancia desmedida a la oferta de justicia. La FES buscó entonces poner el relieve en la demanda de justicia mediante el apoyo a programas de acceso al sistema judicial, entre los que se destacaron los destinados a promover el uso de la conciliación y la mediación por parte de miembros de comunidades marginadas para resolver sus disputas. La FES también decidió impulsar programas de defensoría pública (esto es, de representación gratuita a acusados que no tienen medios para contratar a un abogado), para responder a la mayor capacidad de los fiscales para investigar delitos.
Sin embargo, durante la tercera fase del programa (1996-1999) el deterioro de las relaciones entre Colombia y Estados Unidos -originado en las acusaciones hechas al presidente Ernesto Samper en el llamado Proceso 8.000- aumentó la presión del gobierno de Estados Unidos por obtener resultados concretos de los proyectos en relación con el castigo a narcotraficantes y la reducción inmediata de los inventarios y demoras judiciales. Dado que las estadísticas sobre impunidad y desempeño de los juzgados y tribunales mostraban que la repercusión de los proyectos había sido leve, la AID exigió cambios que dieran lugar a resultados positivos inmediatos. La FES se opuso al enfoque de corto plazo de la AID y se retiró del programa (Arenas y Gómez, 2001; y Santos, 2001).

Tras esta crisis, el programa de la AID entró en declive, y probablemente habría terminado de no haber sido por la creación del llamado Plan Colombia, mediante el cual el gobierno de Estados Unidos aumentó considerablemente los fondos y los programas de asistencia militar e institucional a Colombia. Aunque el Plan Colombia, aprobado en 2000 e iniciado en 2001, es fundamentalmente un programa militar -como lo muestra el hecho de que aproximadamente el $75 \%$ de los fondos estén destinados al gasto militar (CIP, 2004)incluye también fondos para fortalecimiento institucional, que han sido invertidos principalmente en la continuación del programa de reforma judicial de la AID. De esta manera, en 2001 se inició la cuarta fase del programa, administrada por la firma consultora estadounidense Checchi, cuyas actividades están proyectadas hasta 2006.

La cuarta fase presenta tanto continuidad como cambios en relación con las fases anteriores. En cuanto a lo primero, el objetivo central del programa sigue siendo el fortalecimiento del aparato de investigación y acusación, mediante la pro-

Entrevista realizada por Carolina Rondón y Gabriel Gómez, Bogotá, diciembre de 1996. 
moción exitosa de una reforma constitucional y legal, concertada con una comisión interinstitucional de las ramas del poder público colombiano, para instaurar integralmente el modelo del sistema acusatorio oral y, por lo tanto, convertir a la Fiscalía en un ente acusador especializado sin las funciones judiciales híbridas que le fueron otorgadas por la Constitución de 1991. Este proyecto, al que la AID ha destinado cerca de siete millones de dólares (Checchi-AID, 2003), llevó a la reforma constitucional de las funciones de la Fiscalía mediante el Acto Legislativo 03 de 2002 y a la expedición de un nuevo Código de Procedimiento Penal en agosto de 2004. Con la entrada en vigencia de este nuevo sistema acusatorio en algunas regiones del país en enero de 2005, el transplante institucional impulsado por la AID durante más de diez años finalmente tomó forma.

Al tiempo, la cuarta fase presenta algunas innovaciones destacables. Para contrarrestar parcialmente el considerable poder del nuevo ente acusatorio, la AID dedicó fondos para fortalecer el sistema de defensoría pública, aunque su monto (tres millones de dólares) continúa siendo sustancialmente menor al dedicado al fortalecimiento de la parte acusatoria. Igualmente, financió en colaboración con el Ministerio de Justicia la promoción de mecanismos alternativos de conflictos como la mediación comunitaria, objetivo al que han sido dedicados cuatro millones de dólares. Finalmente, la AID continuó y profundizó su programa de acceso a la justicia en zonas urbanas y rurales marginales mediante la construcción de 42 casas de justicia, en el que se invirtieron ocho millones de dólares (Checchi-AID, 2003).

Tras casi veinte años de funcionamiento de los programas de la AID en Colombia, ¿cuál es el balance de sus logros y fracasos? Los proyectos de la AID en Colombia han contribuido a reformas importantes, como el mejoramiento de la investigación criminal. Aunque están por verse los resultados del nuevo sistema acusatorio y su impacto tanto sobre los índices de impunidad como sobre las garantías procesales individuales, la importancia de promover una justicia penal más ágil y transparente es evidente. Los programas de la AID también han sido relativamente permeables a la influencia de las instituciones colombianas que han participado en ellos, tal como lo muestran algunos los esfuerzos limitados por atender el problema del acceso a la justicia y mediación comunitaria en la tercera fase y el esfuerzo mucho más decidido en este sentido en la presente fase.

Sin embargo, las reformas mencionadas han tenido tres rasgos negativos. En primer lugar, las políticas de la AID han sido orientadas fundamentalmente por las prioridades de la política exterior estadounidense -particularmente las de la llamada guerra contra las drogas-, antes que por las necesidades del sistema judicial colombiano. El interés por la persecución de narcotraficantes ha llevado a la AID a dedicar una cantidad desproporcionada de sus recursos a la Fiscalía, en detrimento de otros sectores del sistema judicial que continúan siendo muy precarios. Como se explicó, esta tendencia también ha afectado negativamente la cooperación de las instituciones judiciales locales con el programa.

En segundo lugar, la presión de la AID por obtener resultados inmediatos y tangibles, en términos del número de condenas producidas por el sistema judicial penal, ha relegado a un segundo plano esfuerzos de largo plazo destinados a eliminar las causas de la ineficiencia judicial. De hecho, dicha presión ha sido contraproducente aun en términos de la investigación de crímenes graves. Como lo muestra Rubio (2001), bajo el sistema anterior los fiscales tendieron a concentrarse en la resolución de casos fáciles, que les permitían lograr condenas rápidas $y$, así, aumentar el número de investigaciones 'exitosas' que 
llevaban a cabo, número que era utilizado como criterio para evaluar su labor.

Finalmente, a pesar de los recursos dedicados a la defensoría pública durante la presente fase, es claro que el efecto de las reformas ha sido asimétrico, en la medida en que han contribuido a construir un sistema acusatorio fuerte sin construir de manera concomitante un sistema de defensa y de garantías procesales igualmente eficaz. De ahí que tanto algunas de las reglas del nuevo procedimiento penal como, sobre todo, la insuficiencia de recursos y la capacidad técnica de la defensoría pública a cargo de la Defensoría del Pueblo hoy en día impidan el funcionamiento de un sistema acusatorio equitativo (Comisión Colombiana de Juristas, 2004).

Para los efectos de este capítulo, la principal conclusión del estudio de caso es que las tensiones en el interior del proyecto de la AID se han solucionado a favor del objetivo central de dicho programa: fortalecer el aparato penal colombiano, con frecuencia en detrimento de las garantías procesales individuales, para restaurar la 'ley y el orden' $-\mathrm{y}$, en particular, para impulsar la infructuosa y costosa (en términos de recursos y de vidas humanas colombianas) guerra contra las drogas-.

A pesar de la inclusión de proyectos adjuntos sobre otros temas (acceso, alternativas de resolución de conflictos, etc.), el enfoque nítido del proyecto - reafirmado en momentos de crisis interna- ha sido el aumento del control social y la capacidad punitiva del Estado. Dado que la restauración de la 'ley y el orden' es vista como la condición esencial para el funcionamiento de los mercados (Montenegro y Posada, 2001), las reformas de este tipo encajan bien en la visión convencional del derecho, la justicia y el desarrollo que ha predominado en la segunda generación de reformas.

\section{Conclusiones}

La historia reconstruida en este trabajo es la de una corriente de pensamiento y políticas públicas tan importante como sorprendente. Tras una primera generación fallida, los proyectos de derecho y desarrollo han resurgido con una fuerza inusitada bajo la forma de políticas regionales y globales de reforma al sistema judicial. Como se vio en la sección anterior, dadas las aspiraciones e inversiones involucradas, es probable que la segunda generación tenga una duración y unas repercusiones más profundas que los viejos programas de reforma a la enseñanza del derecho. En vista de esto -y de que la segunda generación está en plena ejecución-, conviene terminar con una conclusión abierta que haga un balance preliminar de los proyectos y ofrezca algunas pistas sobre su trayectoria futura.

El balance debe ser hecho desde dos puntos de vista: uno interno, que evalúe los programas de acuerdo con los objetivos que ellos mismos se han trazado, y otro externo, que examine críticamente estos objetivos y los resultados de los proyectos a la luz de una concepción del sistema judicial y el Estado de derecho más amplia, que difiere de la que inspira dichos programas. Desde el punto de vista interno, evaluaciones recientes, hechas por las organizaciones promotoras y analistas cercanos a ellas, coinciden en afirmar que los resultados de los proyectos de reforma judicial se han quedado muy cortos en relación con los objetivos que se han propuesto, y que la escasez de los resultados obtenidos no corresponde con la muy considerable inversión de fondos y esfuerzo. Por ejemplo, Thomas Carothers, uno de los principales observadores internos de las reformas globales a la justicia, concluye que los efectos de éstas han sido "modestos", por cuanto:

Tras más de diez años y cientos de millones de dólares en ayuda, muchos sistemas judiciales en 
América Latina continúan teniendo un desempeño pobre [...] Las agencias que promueven los programas han ayudado a rescribir leyes alrededor del mundo, pero han descubierto que éstas no generan cambios sustanciales si no se hace un esfuerzo considerable por cambiar las condiciones de su aplicación. Muchos consultores involucrados en programas de fortalecimiento del Estado de derecho son novatos en el mundo de la cooperación internacional y no han aprendido que ésta debe respaldar procesos de cambio que tengan raíces locales, en lugar de reproducir artificialmente modelos o resultados preseleccionados [...] Grandes programas de reforma judicial en Rusia, El Salvador, Guatemala y otros países, patrocinados por Estados Unidos, han naufragado por suponer que la ayuda externa puede sustituir la voluntad interna de reforma (2006: 11).

En este sentido, según el mismo Carothers (2006: 7), la segunda generación ha tenido algún éxito en el tipo de reformas más sencillo pero de menores repercusiones -esto es, las reformas a la legislación-, pero está muy lejos de los resultados esperados en relación con los dos tipos de reformas más arduos e importantes -esto es, la transformación efectiva de las instituciones que administran justicia, por un lado, y la garantía de respeto a la ley y las decisiones judiciales independientes por parte de los gobiernos, por el otro. En suma, incluso cuando se evalúan en sus propios términos, los proyectos han arrojado hasta ahora resultados que están lejos del modelo de sistema judicial y Estado de derecho que los ha inspirado (véase también Jensen, 2004).

Si, como lo he propuesto, complementamos esta visión interna con una evaluación externa basada en una visión más comprehensiva de la justicia y el Estado de derecho, se hacen visibles otras limitaciones y vacíos de los proyectos de reforma judicial. Como lo mostré en las secciones precedentes, tanto la teoría como la práctica de la segunda generación apuntan a un sistema judicial y un Estado de derecho de baja intensidad, basa- dos en una visión selectiva de uno y otro que hace hincapié en las garantías de libertad económica y seguridad, en detrimento de los derechos de igualdad que son también componentes esenciales de la democracia y el Estado de derecho. Esta versión de alta intensidad de la justicia y el Estado de derecho es precisamente la que contemplan las constituciones contemporáneas que, como la colombiana de 1991, han adoptado el modelo del Estado social de derecho como principio de organización institucional.

Reformas que, como las analizadas acá, marginan los componentes garantistas e igualitarios del Estado de derecho, se encuentran invariablemente con serios problemas de legitimidad, equidad y eficacia. A la luz del análisis hecho en dicho capítulo, no sorprende que los proyectos de segunda generación hayan tenido resultados tan limitados. De hecho, éstos confirman la tendencia secular al fracaso de las reformas jurídicas latinoamericanas, que en muchas ocasiones han terminado reforzando la corrupción y la desigualdad ante la ley que intentaban mitigar. Como concluyen Jeremy Adelman y Miguel Centeno en su análisis histórico del Estado de derecho en América Latina, si los proyectos reformistas no contrarrestan los hondos problemas de desigualdad social que impiden el funcionamiento de instituciones eficientes, legítimas y equitativas, las transformaciones institucionales lograrán poco porque "las clases más pudientes usan incluso las instituciones y reglas 'reformadas' para reforzar el patrón de aplicación desigual de la ley" (2002: 158). Dado que, como vimos, la aplicación igual de la ley a gobernantes y gobernados, a ricos y a pobres, constituye la definición misma del Estado de derecho, sin este componente las reformas continuarán arrojando resultados desalentadores.

Por esto, proponemos una aproximación teórica y práctica a la justicia que, al lado de instituciones facilitadoras del mercado, incorpore y dé priori- 
dad a mecanismos de inclusión social (por ejemplo, instituciones que garanticen el acceso igualitario a la justicia) y de protección de las garantías individuales que tienden a ser sacrificadas por políticas que buscan endurecer la capacidad represiva del Estado (por ejemplo, las garantías del debido proceso y la libertad personal en la justicia penal). Aunque la reducción de los inventarios de casos pendientes, las demoras en los trámites judiciales y los índices de impunidad son ciertamente fines importantes y condiciones necesarias de un sistema judicial eficiente y equitativo, no son suficientes para la consolidación de un Estado de derecho y una democracia robustos, en los que el goce de los derechos constitucionales y legales sea garantizado a los ciudadanos de cualquier condición social, económica o cultural. En resumen, el enfoque que proponemos coincide con la segunda generación en resaltar la importancia de la transformación de la justicia y las instituciones, pero difiere de aquélla en las prioridades reformistas. De ahí que, en contraposición con el institucionalismo de corte (neo)liberal que subyace a los programas arriba analizados, propongamos lo que hemos llamado institucionalismo social.

Desde esta perspectiva, sugiero tres frentes en los que deben concentrarse las políticas de reforma judicial en el país y la región. En primer lugar, debe promoverse la aplicación de los derechos sociales, económicos y culturales. A pesar de la incorporación de derechos sociales en nuevas constituciones por toda Latinoamérica -por ejemplo, en Brasil (1988), Colombia (1991) y Venezuela (1999)-, su aplicación es todavía muy precaria. El potencial de justicia social contenido en esos derechos puede ser explotado mediante la introducción de reformas que establezcan, por ejemplo, acciones judiciales eficaces que permitan a los ciudadanos pedir a los jueces aplicar esos derechos en casos cotidianos. No obstante los avances logrados en esta dirección -como el éxito moderado de la acción de amparo constitucional (acción de tutela) en la protección de dichos derechos en Colombia (Cijus, 1998)-, queda todavía mucho por hacer para promover mecanismos legales e instituciones judiciales que hagan efectivos los derechos sociales.

En segundo lugar, el problema del acceso a la justicia debe ser tomado en serio. Tradicionalmente, el acceso a la justicia fue objeto de debates ocasionales y de pequeños proyectos que acompañaban los programas de reforma judicial en América Latina. Esta falla, reproducida en la fase inicial de los programas de segunda generación, hoy parece estar contrarrestándose por numerosos proyectos incluidos en las políticas de reforma judicial. Como lo han puesto de presente O’Donnell, Méndez y Pinheiro (1999) en su análisis de la situación actual del Estado de derecho en América Latina, no tiene sentido una reforma cuyo resultado sea una justicia eficiente pero accesible sólo para una minoría privilegiada. Por lo tanto, la reforma judicial y los programas de acceso a la justicia deben ser emprendidos de forma simultánea, y se deben destinar fondos y esfuerzos suficientes para atender los dos frentes. Esta es la recomendación que surge de otros estudios empíricos sobre el tema, que muestran que las reformas más exitosas y sostenibles son aqueIlas que invierten esfuerzos y fondos similares en la promoción de la independencia, la eficiencia y el acceso a la justicia (Prillaman, 2000; Jensen, 2004).

Los programas de acceso a la justicia deben incluir una amplia gama de reformas. Especial importancia tiene la creación de un sistema eficiente y adecuado de defensoría pública para quienes no tienen los medios para contratar a un abogado. Las deficiencias de los sistemas jurídicos de la región en este aspecto son alarmantes. Por ejemplo, un estudio del Consejo Superior de la Judicatura de Colombia (1998) encontró que las posibilidades de que un acusado sea condenado en un juicio penal son $\mathbf{8 0} \%$ mayores cuando 
el acusado está representado por un defensor público, que cuando está representado por un abogado privado. Por lo tanto, a pesar de que se inviertan cuantiosas sumas en adquirir computadores y equipos de alta tecnología para los jueces penales y fiscales, el sistema judicial como un todo seguirá siendo altamente inequitativo si los problemas del acceso a la justicia y la defensoría pública no son enfrentados.

Finalmente, el énfasis actual en la reforma de los juzgados civiles y comerciales en América Latina (y, en Colombia, en la reforma de la investigación de los delitos) debe ser complementado por la atención a sectores del sistema judicial que han ocupado hasta ahora un lugar secundario en los programas. Por ejemplo, es fundamental promover la reforma y el fortalecimiento de los juzgados y las demás instituciones encargadas de resolver los conflictos que involucran a sectores vulnerables de la población. Este es el caso, por ejemplo, de los juzgados y comisarías de familia, que conocen las disputas por violencia intrafamiliar contra mujeres y menores de edad, y de los juzgados laborales, que procesan las disputas surgidas de violaciones de los derechos de los trabajadores. Reformas como la creación de juzgados de pequeñas cuantías y de mecanismos de resolución alternativa de conflictos bajo la supervisión estatal en estos sectores, que han sido dejadas de lado en los proyectos de segunda generación, deben ser consideradas seriamente para ofrecer protección eficaz a estas y otras poblaciones en estado de subordinación o indefensión.

En síntesis, la profunda revisión de las políticas actuales de reforma al derecho y las instituciones judiciales en América Latina, mediante estrategias como las propuestas, es una condición indispensable para que dichas políticas contribuyan a consolidar el Estado social de derecho en la región. Sólo cambios de este tipo, como algunas de las agencias que financian los programas parecen haberlo comenzado a entender, podrían evitar un segundo fracaso de la corriente de derecho y desarrollo en América Latina.

\section{BIBLIOGRAFÍA}

ADELMAN, Jeremy y CENTENO, Miguel. 2002. "Between liberalism and neoliberalism: law's dilemma in Latin America", en DEZALAY, Yves y GARTH, Bryant (eds.), Global prescriptions. The production, exportation, and importation of a new legal orthodoxy. Ann Arbor: The University of Michigan Press, pp. 139-161.

ADELMAN, Sammy y PALIWALA, Abdul (eds.). 1993. Law and Crisis in the Third World. New York: Hanz Hell.

ARENAS, Luis Carlos y GÓMEZ, Gabriel. 2000. Looking for justice in the time of rule of law programs. Case studies of Colombia, Peru and Venezuela. Tesis. Madison: University of Wisconsin.

BANCO MUNDIAL. 2002. Legal and judicial reform: observations, experiences and approach of the legal vice presidency. Washington: Banco Mundial.

BANCO INTERAMERICANO DE DESARROLLO (BID). 1998. Justice delayed. Judicial reform in Latin America. Washington.

-. 1993. Justice and development in Latin America and the Caribbean. Washington.

BIEBESHEIMER, Christina. 2001. "Justice reform in Latin America and the Caribbean. The IDB perspective", en DOMINGO, Pilar y SIEDER, Rachel (eds.). Rule of law in Latin America. The international promotion of judicial reform. London: Institute for Latin American Studies, University of London, pp. 99-141.

BUSCAGLIA, Edgardo. 1998. "Obstacles to judicial reform in Latin America", en BID. Justice 
delayed. Judicial reform in Latin America. Washington, pp. 15-30.

CAO, Lan. 1992. "Law and economic development. A new beginning?", en Texas International Law Journal, No. 32, pp. 545-559.

CARTY, Anthony (ed.). 1995. Law and development. Dartmouth: Gower House.

CAROTHERS, Thomas. 2006a. "The rule of law revival", en CAROTHERS, Thomas (ed.). Promoting the rule of law abroad. In search of knowledge. Washington: Carnegie Endowment for International Peace, pp. 3-14..

- (ed.). 2006b. Promoting the rule of law abroad. In search of knowledge. Washington: Carnegie Endowment for International Peace.

-. 2001. "The many agendas of rule-of-law reform in Latin America", en DOMINGO, Pilar y SIEDER, Rachel (eds.). Rule of law in Latin America. The international promotion of judicial reform. London: Institute for Latin American Studies, University of London, pp. 4-16..

CARRILLO, Fernando. 1998. "The Inter-American Development Bank", en BID. Justice delayed. Judicial reform in Latin America. Washington, pp. 149-155.

CENTRO DE INVESTIJACIONES SOCIOJURÍDICAS (CIJUS). 1998. Análisis sociojurídico de la acción de tutela. Bogotá: Universidad de Los Andes.

CHECCHI-AID. 2003. Programa de fortalecimiento y acceso a la justicia. Bogotá (mimeo).

CHIBUNDU, Maxwell O. 1997. "Law in development. On tapping, gourding and serving palm-wine", en Case Western Reserve Journal of International Law, No. 29, pp. 167-262.
CENTER FOR INTERNATIONAL POLICY (CIP). 2004.

"U.S. military and police aid" (www.ciponline.org/colombia).

CONSEJO SUPERIOR DE LA JUDICATURA, Colombia. 1998. Balance sociojurídico de la justicia penal en Colombia. 1996-1997. Bogotá.

COMISIÓN COLOMBIANA DE JURISTAS. 2004. “Código de Procedimiento Penal. Una oportunidad perdida", en Actualidad Colombiana, agosto 18-septiembre 1, pp. 2-3.

CORTÉS, Juan. 1995. Diagnóstico cooperativo de la cooperación técnica internacional en el sector justicia 1990-1994. Bogotá: Sipeci.

DAKOLIAS, Maria. 2001. "Legal and judicial reform. The role of civil society in the reform process", en DOMINGO, Pilar y SIEDER, Rachel (eds.). Rule of law in Latin America. The international promotion of judicial reform. London: Institute for Latin American Studies, University of London, pp. 80-98.

-. 1996. The judicial sector in Latin America and the Caribbean. Washington: The World Bank.

DEZALAY, Yves y GARTH, Bryant. 2002. La internacionalización de las luchas por el poder. La competencia entre abogados y economistas por transformar los Estados latinoamericanos. Bogotá: ILSA y Universidad Nacional de Colombia.

DOMINGO, Pilar y SIEDER, Rachel (eds.). 2001a. Rule of law in Latin America. The international promotion of judicial reform. London: Institute for Latin American Studies, University of London.

-. 2001b. "Conclusions. Promoting the rule of law in Latin America", en DOMINGO, Pilar y SIEDER, Rachel (eds.). Rule of law in Latin America. The international promotion of judicial reform. 
London: Institute for Latin American Studies, University of London, pp. 142-164..

FUNDACIÓN FORD. 2000. Many roads to justice. The law-related work of Ford Foundation grantees around the world, Nueva York.

GARCÍA, Lucía. 1995. Informe de cooperación técnica internacional. Programa AID. Bogotá: Ministerio de Justicia.

GARDNER, James. 1980. Legal imperialism. Madison: The University of Wisconsin Press.

GARTH, Bryant y DEZALAY, Yves. 1998. Dealing in virtue. International commercial arbitration and the construction of a transnational legal order. Chicago: Chicago University Press.

GHAI, Yash. 1978. "Law and another development", en Development Dialogue, No. 2, pp. 109-133.

GINSBURG, Tom. 1995. Law and development. The third wave (mimeo). Documento presentado a la Law and Society Association Annual Conference, Toronto, Canadá.

HENAO, Juanita. 1991. La cooperación internacional al desarrollo en Colombia. Bogotá: Cinep.

INTERNATIONAL COMMISSION OF JURISTS (ICJ). 1981. Development, human rights and the rule of law. Exerter: A. Wheaton \& Co.

INTERNATIONAL CENTER FOR LAW IN DEVELOPMENT (ICLD). 1978. "Research priorities for another development in law", en Development Dialogue, No. 2, pp. 134-142.

IGLESIAS, Enrique. 1993. "Law, justice and development in Latin America in the nineties", en BID. Justice and development in Latin America and the Caribbean. Washington: Inter-American Development Bank, pp. 2-6.
INSTITUTO LATINOAMERICANO DE SERVICIOS LEGALES ALTERNATIVOS (ILSA), (ed.). 2001. El otro derecho. Nuevos caminos para la administración de justicia. Bogotá.

INTERNATIONAL LEGAL CENTER (ILC). 1975. Legal education in a changing world. Uppsala: Uppsala Offset Center AB.

-. 1974. Law and development. Uppsala: Uppsala Offset Center AB.

JARQUÍN, Edmundo y CARRILLO, Fernando. 1998. "Introduction", en BID. Justice delayed. Judicial reform in Latin America. Washington: InterAmerican Development Bank, pp. v-xi.

JENSEN, Erik G. (ed.). 2004. Beyond common knowledge. Empirical approaches to the rule of law. Stanford: Stanford University Press.

KECK, Margareth y SIKKINK, Kathryn. 1998. Activists beyond borders. Ithaca: Cornell University Press.

KENNEDY, David. 2006. "Political choices and development common sense", en TRUBEK, David y SANTOS, Álvaro (eds.). The new law and economic development. A critical appraisal. Cambridge: Cambridge University Press, pp. 103-131.

MARTíNEZ, Néstor Humberto. 1998. "Rule of law and economic efficiency", en BID. Justice delayed. Judicial reform in Latin America. Washington: Inter-American Development Bank, pp. 3-14.

MCMICHAEL, Philip. 2000. Development and social change. A global perspective. Thousand Oaks: Pine Forge Press.

MONTENEGRO, Armando y POSADA, Carlos Esteban. 2001. La violencia en Colombia. Bogotá: Alfaomega-Cambio. 
NAíM, Moisés. 2000. "Washington consensus or Washington confusion?", en Foreign policy, primavera, pp. 87-103.

-. 1994. Latin America's journey to the market. From economic shocks to institutional therapy. San Francisco: International Center for Economic Growth.

NORTH, Douglass C. 1990. Institutions, institutional change and economic performance. Cambridge: Cambridge University Press.

NORTH, Douglass C.; SUMMERHILL, William, y WEINGAST, Barry. 2002. “Orden, desorden y cambio económico. Latinoamérica vs. Norteamérica", en Revista Instituciones y Desarrollo, No. 12-13, pp. 9-59.

OBANDO, Jorge. 1998. "The United Nations Development Program", en BID. Justice delayed. Judicial reform in Latin America. Washington: Inter-American Development Bank, pp. 143-149.

O'DONNELL, Guillermo; MÉNDEZ, Juan, y PINHEIRO, Paulo (eds.). 1999. The (un)rule of law and the underprivileged in Latin America. Notre Dame: University of Notre Dame Press.

O GLOBO. 2003. “PT tomará frente da reforma do Judiciario", noviembre 4, p. 1-3.

PRILLAMAN, William. 2000. The judiciary and democratic decay in Latin America. Westport: Praeger.

RODRÍGUEZ GARAVITO, César A. 2006. “Alternative law", en CLARK, David (ed.). Encyclopedia of law and society. American and global perspectives. Thousand Oaks: Sage, pp. 15461547.
-. 2005. "Global governance and labor rights. Codes of conduct and anti-sweatshop struggles in global apparel factories in Mexico and Guatemala", en Politics \& Society, vol. 33, No. 2, pp. 203-233.

-. 1999. "Una crítica a la doctrina liberal de la imparcialidad de los jueces. En torno al impacto de los estudios críticos del derecho en América Latina", en: KENNEDY, Duncan. Libertad y restricción en la decisión judicial. Bogotá: Siglo del Hombre, pp. 17-88.

RONDÓN, Carolina. 1998. La cooperación internacional en materia de justicia en Colombia. Tesis de grado. Bogotá: Universidad de Los Andes, Facultad de Derecho..

ROWAT, Malcom; MALIK, Waleed; y DAKOLIAS, Maria (eds.). 1995. Judicial reform in Latin American and the Caribbean. Washington: The World Bank.

RUBIO, Mauricio. 2001. "La justicia penal", en SANTOS, Boaventura y GARCÍA, Mauricio (dirs.). El caleidoscopio de las justicias en Colombia. Bogotá: Uniandes-Siglo del HombreColciencias-CES, pp. 485-546.

SACHS, Jeffrey. 1999. Globalization and the rule of law. New Haven: Yale University Press.

SALAS, Luis. 2001. "From law and development to rule of law. New and old issues in justice reform in Latin America", en DOMINGO, Pilar y SIEDER, Rachel (eds.). Rule of law in Latin America. The international promotion of judicial reform. London: Institute for Latin American Studies, University of London, pp. 17-46.

SANTOS, Boaventura de Sousa. 2005. "Beyond neoliberal governance. The World Social Forum as subaltern cosmopolitan politics and 
legality", en SANTOS, Boaventura de Sousa y RODRíGUEZ GARAVITO, César A. (eds.). Law and globalization from below. Toward a cosmopolitan legality. Cambridge: Cambridge University Press, pp. 29-63.

-. 2001. "Derecho y democracia. La reforma global de la justicia", en SANTOS, Boaventura y GARCÍA, Mauricio (dirs.). El caleidoscopio de las justicias en Colombia. Bogotá: UniandesSiglo del Hombre-Colciencias-CES, pp. 151-208.

SANTOS, Boaventura de Sousa y RODRíGUEZ GARAVITO, César A. 2005. "Law, politics and the subaltern in counter-hegemonic globalization", en SANTOS, Boaventura de Sousa y RODRíGUEZ GARAVITO, César A. (eds.). Law and globalization from below. Toward a cosmopolitan legality. Cambridge: Cambridge University Press, pp.

SARLES, Margaret. 2001. "USAID's support of justice reform in Latin America", en DOMINGO, Pilar y SIEDER, Rachel (eds.). Rule of law in Latin America. The international promotion of judicial reform. London: Institute for Latin American Studies, University of London, pp. 47-79..

SHIHATA, Ibrahim F. I. 1998. "The World Bank", en BID. Justice delayed. Judicial reform in Latin America. Washington: Inter-American Development Bank, pp. 117-132.

-. 1995a. "Judicial reform in developing countries and the role of the World Bank", en ROWAT, Malcom; MALIK, Waleed; y DAKOLIAS, Maria (eds.). Judicial reform in Latin American and the Caribbean. Washington: The World Bank, pp. 2-13..

-. 1995b. "Legal framework for development. The World Bank's role in legal and judicial reform", en ROWAT, Malcom; MALIK, Waleed; y DAKOLIAS, Maria et al. (eds.). Judicial reform in Latin American and the Caribbean. Washington The World Bank, pp. 33-46..

SOUZA, Maria de Lourdes. 2001. El uso alternativo del derecho. Génesis y evolución en Italia, España y Brasil. Bogotá: ILSA y Universidad Nacional de Colombia.

SNYDER, Francis G. 1982. "The failure of law and development", en Wisconsin Law Review, No. 1982. pp. 373-395.

TAMANAHA, Brian. 1995. "Law and development", en The American Journal of International Law, No. 89 , pp. 470-485.

THE ECONOMIST. 2004. “Brazil's judiciary: not-soswift justice", marzo 27, p. 37.

TRUBEK, David M. 2006. "The 'rule of law' in development assistance. Past, present, and future", en TRUBEK, David y SANTOS, Álvaro (eds.). The new law and economic development. A critical appraisal. Cambridge: Cambridge University Press, pp. 21-56.

-. 1990. "Back to the future. The short, happy life of the law and society movement", en Florida State University Law Review, No. 18, pp. 454.

TRUBEK, David y ESSER, John. 1989. "'Critical empiricism' and the american critical legal studies. Paradox, program, or Pandora box?", en Law and Social Inquiry, No. 14, pp. 3-52.

TRUBEK, David y GALANTER, Marc. 1974. "Scholars in self-estrangement. Some reflections on the crisis in law and development studies in the United States", en Wisconsin Law Review, No., 1974, pp. 1062-1102. 
TRUBEK, David y SANTOS, Álvaro (eds.). 2006. The new law and economic development. A critical appraisal. Cambridge: Cambridge University Press.

UPRIMNY, Rodrigo. 1994. "Fiscal general o General fiscal", en Revista del Colegio de Abogados Penalistas del Valle, No. 20, pp. 18-37.

VAKY, Paul. 1998. "U.S. Agency for International Development", en BID. Justice delayed. judicial reform in Latin America. Washington: InterAmerican Devlopment Bank, pp. 137-142.
VERBITSKY, Horacio. 1993. Hacer la Corte. Buenos Aires: Planeta.

WATSON, Alan. 1974. Legal transplants. Charlottesville: The University Press of Virginia.

WILLIAMSON, John. 2003. "Summing up", en WILLIAMSON, John y KUCZYNSKI, Pablo (eds.), After the Washington consensus. Restarting growth and reform in Latin America, Washington: Institute for International Economics, pp. 305-321 